Review

www.mdpi.com/journal/materials

\title{
Luminescence from Zinc Oxide Nanostructures and Polymers and their Hybrid Devices
}

\author{
Magnus Willander *, Omer Nur, Jamil Rana Sadaf, Muhammad Israr Qadir, Saima Zaman, \\ Ahmed Zainelabdin, Nargis Bano and Ijaz Hussain
}

Department of Science and Technology (ITN), Campus Norrköping, Linköping University, SE 60174 Norrköping, Sweden ; E-Mails: omeno@itn.liu.se (O.N.); sadra@itn.liu.se (J.R.S.); muhqa@itn.liu.se (M.Q.I.); saiza@itn.liu.se (S.Z.); ahmza@itn.liu.se (A.Z.); narba@itn.liu.se (N.B.); ijaz.hussain@ecospark.se (I.H.)

* Author to whom correspondence should be addressed; E-Mail: magwi@itn.liu.se; Tel.: +46-11-363167; Fax: +46-11-36 3270.

Received: 4 January 2010; in revised form: 15 March 2010 / Accepted: 31 March 2010 / Published: 12 April 2010

\begin{abstract}
Zinc oxide $(\mathrm{ZnO})$ is a strong luminescent material, as are several polymers. These two materials have distinct drawbacks and advantages, and they can be combined to form nanostructures with many important applications, e.g., large-area white lighting. This paper discusses the origin of visible emission centers in $\mathrm{ZnO}$ nanorods grown with different approaches. White light emitting diodes (LEDs) were fabricated by combining n$\mathrm{ZnO}$ nanorods and hollow nanotubes with different p-type materials to form heterojunctions. The p-type component of the hybrids includes p-SiC, p-GaN, and polymers. We conclude by analyzing the electroluminescence of the different light emitting diodes we fabricated. The observed optical, electrical, and electro-optical characteristics of these LEDs are discussed with an emphasis on the deep level centers that cause the emission.
\end{abstract}

Keywords: $\mathrm{ZnO}$ nanostructures; deep center luminescence; light emitting diodes; hybrid technology 


\section{Introduction}

Zinc oxide ( $\mathrm{ZnO})$, a II-VI direct wide bandgap semiconductor, has been studied by the scientific community since the 1930s [1]. Although it has unique and interesting properties, such as a relatively high exciton binding energy $(60 \mathrm{meV})$, and a wide bandgap $(3.34 \mathrm{eV})$, and is piezoelectric, biologically safe and biocompatible [2], researchers' work with $\mathrm{ZnO}$ has previously been focused on obtaining stable p-type dopants for $\mathrm{ZnO}$. In addition to these excellent properties, $\mathrm{ZnO}$ possesses a large number of extrinsic and intrinsic deep-level impurities and complexes (clusters) that emit light of different colors [2], including violet, blue, green, yellow, orange and red, i.e., all constituents of white light [2-4]. Because of this, $\mathrm{ZnO}$ is considered to be attractive for applications requiring luminescent materials. $\mathrm{ZnO}$, especially in its nanostructure form, is currently attracting intense global interest for photonic applications [2]. ZnO has the additional advantages of being easy to grow and possessing the richest known family of nanostructures [5]. The present global interest in $\mathrm{ZnO}$ nanostructures is motivated by the possibility of growing them on any p-type substrate and hence producing high quality pn heterojunctions [2]. The interest in optoelectronic applications arises from the possibility of developing low energy and environmentally friendly white light emitting technologies and laser diodes that operate above room temperature [2]. The renewed interest in utilizing the excellent properties of $\mathrm{ZnO}$ in optoelectronic devices is mainly due to the $\mathrm{ZnO}$ ambipolar doping problem mentioned above. This problem frequently occurs in wideband gap materials, in which it is very easy to dope the material with one polarity but is very difficult to dope the same material with the other polarity [6]. As $\mathrm{ZnO}$ is naturally n-type, it is very difficult to dope it with materials of p-type polarity [6]. Several laboratories have reported p-type $\mathrm{ZnO}$, but their results were difficult to reproduce in other laboratories and hence remain controversial. Elements from group I, including $\mathrm{Li}, \mathrm{Na}$, and $\mathrm{K}$, as well as elements like $\mathrm{Cu}$ and $\mathrm{Ag}$, are supposed to be good acceptors when replacing a $\mathrm{Zn}$ site, and they form deep acceptors with ionization energies around a few hundred $\mathrm{meV}$ above the valence band [7]. This implies that under normal conditions, i.e., at equilibrium, doping can be achieved without any ionization leading to free holes. Moreover, at high levels of doping with such elements, interstitial Li (or Ag) atoms will act as donors and compensate many acceptors [7-9]. Another possibility for doping $\mathrm{ZnO}$ to p-type is to use elements from group $\mathrm{V}$ on the $\mathrm{O}$ site, including $\mathrm{N}, \mathrm{P}, \mathrm{Sb}$, and As. Nevertheless, most efforts to use these elements have led to poorly reproducible results. An elegant summary of all of these efforts is documented in Look et al. [10]. Most recently, there have been successful reports of doping ZnO with $\mathrm{N}$, forming a level with ionization energy of around $100 \mathrm{meV}$, less than the $160 \mathrm{meV}$ ionization energy of the standard $\mathrm{Mg}$ acceptor in $\mathrm{GaN}$ [6]. Nevertheless, due to the existence of other native deep levels close to the conduction band, the compensation effect makes these efforts unsuccessful in producing stable and highly doped p-type $\mathrm{ZnO}$ materials.

The difficulty in doping $\mathrm{ZnO}$ to p-type polarity has led researchers to seek to create heterojunctions with other p-type semiconductor materials to enable $\mathrm{ZnO}$ to be used in optoelectronic devices. These efforts began by growing n-type $\mathrm{ZnO}$ thin films on p-type substrates. However, due to lattice mismatches, most of these efforts have not led to the development of device-quality heterojunctions. The efforts in growing thin films of n-type $\mathrm{ZnO}$ on different $\mathrm{p}$-type substrates, along with many of the fundamental properties of $\mathrm{ZnO}$, are described in the comprehensive review written by Özgur et al. [11]. Nano-structures, especially nanorods or nanowires, possess a relatively large surface area to 
volume ratio, enabling them to release stress and strain due to lattice mismatch with other materials. In addition, $\mathrm{ZnO}$ has been shown to be able to produce a rich family of different nanostructures; as a wurtzite structure, $\mathrm{ZnO}$ has a total of 13 different facet growth directions: $<0001>,<01-10>,<2$ $-1-10>$. Together with a pair of polar surfaces $\{0001\}$, this uniquely structured material has been demonstrated to form a diverse group of nanostructures: nanorods, nanobelts, nanocombs, nanosprings, nanorings, nanobows, nanojunction arrays, and nanopropeller arrays, which are formed largely due to the highly ionic character of the polar surfaces [12]. Some $\mathrm{ZnO}$ nanostructures (namely tetrapods) were unintentionally synthesized as early as 1944 [13]. At that time, there were no microscopes with sufficient resolution to view the synthesized structures, which have since been identified as tetrapods [13]. The different growth methods used to obtain $\mathrm{ZnO}$ nanostructures can be divided into two main groups: low $\left(<100{ }^{\circ} \mathrm{C}\right.$ ) and high (up to $1000{ }^{\circ} \mathrm{C}$ ) temperature techniques. Willander et al. provide a thorough review of these different growth techniques; the reader is directed to [2]. High quality $\mathrm{ZnO}$ nanostructures have been grown on a variety of crystalline as well as amorphous (polymer) substrates and formed excellent pn heterojunctions, in contrast to thin films of $\mathrm{ZnO}$, which have shown very limited success in forming heterojunctions. One advantage of $\mathrm{n}$ - $\mathrm{ZnO}$ nanorods on any $\mathrm{p}$-substrate is that each nanorod will form a discrete, separated pn junction, and hence a large-area light emitting diode can be designed without compromising the junction area, which would lead to large reverse leakage currents. This is an important property that is advantageous for large-area lighting commercialization.

This paper discusses the different native point defects in $\mathrm{ZnO}$ together with their relevant luminescent properties. The origin of the different deep-level emission bands usually observed in $\mathrm{ZnO}$ is briefly reviewed. This discussion is followed by examples of recently fabricated light emitting diodes (LEDs) based on $\mathrm{ZnO}$ nanorods and nanotubes, fabricated using different crystalline and amorphous p-type substrates. The electrical, optical and electro-optical characteristics of these visible light emitting diodes will all be discussed in connection to the deep-level defects present in different $\mathrm{ZnO}$ nanorods and nanotubes grown by high or low temperature techniques. We will present results from LEDs grown by low temperature chemical growth at temperatures as low as $50{ }^{\circ} \mathrm{C}$ on plastic flexible substrates coated with p-type polymers suitable for large area lighting.

\section{Luminescent Centers in $\mathrm{ZnO}$}

Efficient donors and acceptors have energy levels near the conduction and valence bands, respectively; deep centers also exist with energy levels deep in the forbidden gap. The room temperature photoluminescence (PL) spectrum of $\mathrm{ZnO}$ nanorods/nanowires with diameters larger than $20 \mathrm{~nm}$ is similar to the PL spectra of bulk $\mathrm{ZnO}$. This room temperature PL spectrum is normally characterized by near-band-edge (NBE) ultra-violet (UV) emission and at least one broad band emission due to deep levels, called DLE. DLE refers to the broad band extending from just above 400 $\mathrm{nm}$ up to $750 \mathrm{~nm}$, i.e., the whole visible spectrum. The broadness of the band results from the fact that it represents a superposition of many different deep levels emitting at the same time. Different reports have suggested different deep levels as the origin of the observed emissions. Before discussing the origin of the deep band emissions, it is important to discuss most of the known deep levels in $\mathrm{ZnO}$ and some of their important properties such as their formation energy and contribution to conductivity. 
Although no consensus exists on the origin of the broad deep band emission, the broad nature of the emission suggests the possibility that it is a combination of many emissions. The deep levels of $\mathrm{ZnO}$ are divided into extrinsic and intrinsic deep levels.

The possible intrinsic 'native' deep levels in $\mathrm{ZnO}$ are oxygen vacancy $\left(\mathrm{V}_{\mathrm{O}}\right)$, zinc vacancy $\left(\mathrm{V}_{\mathrm{Zn}}\right)$, oxygen interstitial $\left(\mathrm{O}_{\mathrm{i}}\right)$, zinc interstitial $\left(\mathrm{Zn}_{\mathrm{i}}\right)$, oxygen anti-site $\left(\mathrm{O}_{\mathrm{Zn}}\right)$, and zinc anti-site $\left(\mathrm{Zn}_{\mathrm{O}}\right)$. This is in addition to native defect clusters, which are usually formed by the combination of two point defects or one point defect and one extrinsic element, e.g., a $\mathrm{V}_{\mathrm{O}} \mathrm{Zn}_{\mathrm{i}}$ cluster formed by $\mathrm{Zn}_{\mathrm{i}}$ and $\mathrm{V}_{\mathrm{O}}$. This $\mathrm{V}_{\mathrm{O}} \mathrm{Zn}_{\mathrm{i}}$ cluster is one of the clusters that has been previously identified and is situated $2.16 \mathrm{eV}$ below the conduction band minimum. These native point defects often directly or indirectly control doping, compensation, minority carrier lifetime and luminescence efficiency in semiconductors [14]. Native defects are often invoked to explain the fact that $\mathrm{ZnO}$ always exhibits a high level of unintentional $\mathrm{n}$ type conductivity. Even the difficulty in obtaining stable p-type doping is closely related to a compensation effect connected to intrinsic native defects that lie in the forbidden gap (deep centers). We will review the basic properties of these different native defects below. The following discussion is mainly based on results obtained using a comprehensive, first-principles investigation of native point defects in $\mathrm{ZnO}$ using density functional theory within the local density approximation [14]. The concentration of a point defect depends on its formation energy. At thermodynamic equilibrium and in dilute cases (no defect-defect interaction), the concentration of a point defect (c) is given by [14]:

$$
c=N_{\text {sites }} \exp \left(-\frac{E^{f}}{k_{B} T}\right)
$$

where $\mathrm{c}$ is the point defect concentration, $E^{f}$ is the formation energy, $N_{\text {Sites }}$ is the number of available sites to accommodate the defect, $\mathrm{k}_{\mathrm{B}}$ is Boltzmann's constant, and $\mathrm{T}$ represents temperature. According to equation 1, defects with high formation energies will occur at low concentrations. The formation energy $E^{f}$ of point defects is not constant, but rather depends on the growth parameters and annealing conditions [15]. The formation energy of an oxygen vacancy depends on the abundance of oxygen and zinc atoms in the growth environment. Furthermore, if the vacancy is charged then the formation energy depends on the Fermi level $\left(\mathrm{E}_{\mathrm{F}}\right)$, i.e., the electron chemical potential. The chemical potential depends on the growth conditions, which can either be oxygen-rich, zinc-rich or in between these two extremes. Hence, the chemical potential is usually treated as a variable and is chosen according to certain rules. In reality, the growth environment controls the concentration of native defects in $\mathrm{ZnO}$. For further details on the limitations of chemical potential values, the reader is advised to Janotti et al. and van de Walle et al. [14-15]. As discussed above, these deep levels introduce levels in the bandgap of the semiconductor that involve transitions between different charge states. The transition levels can be experimentally observed when the final charge state fully relaxes to its equilibrium configuration after the transition, such as in deep level transient spectroscopy (DLTS) [16]. Conventionally, if the transition level is situated such that the defect is most likely to be ionized at room temperature or at the device operating temperature, then this is called a shallow transition level [14]. If the transition level is unlikely to be ionized at room temperature, then it is a deep transition level. The first step in the discussion on deep level native defects in $\mathrm{ZnO}$ is to consider $\mathrm{V}_{\mathrm{O}} . \mathrm{V}_{\mathrm{O}}$ and $\mathrm{Zn}_{\mathrm{i}}$ have long been suggested to be sources of the observed unintentional doping in $\mathrm{ZnO}$, which is due to 
shallow levels situated $30-40 \mathrm{meV}$ below the conduction band minima $[17,18]$. The assignment of $\mathrm{V}_{\mathrm{O}}$ or $\mathrm{Zn}_{\mathrm{i}}$ to the unintentional $\mathrm{n}$-type doping originated from the fact that the growth of $\mathrm{ZnO}$ crystals was typically performed in a $\mathrm{Zn}$-rich environment, and hence the dominant native defects were assumed to be $V_{O}$ and $Z_{n}$. Nevertheless, recent careful theoretical study revealed that this claim was incorrect for both $V_{O}$ and $Z n_{i}$, as will be discussed below [14]. The formation energy of $V_{O}$ was found to be quite high in $\mathrm{n}-\mathrm{ZnO}$ material, even under extreme conditions, where it has a value of $3.27 \mathrm{eV}$. According to equation $1, \mathrm{~V}_{\mathrm{O}}$ will always occur in low concentrations under equilibrium conditions, and it is not expected to be the source of the unintentional n-type doping. According to the energy calculations, isolated $\mathrm{V}_{\mathrm{O}}$ cannot be the source of electrons in the conduction band in $\mathrm{ZnO}$. In fact, in p-type doped $\mathrm{ZnO}, \mathrm{V}_{\mathrm{O}}$ assumes a $2+$ charge state and hence provides a potential source of compensation in p-type $\mathrm{ZnO}$ [14]. This theoretical investigation [14] was consistent with experimental evidence from positron annihilation spectroscopy studies $[19,20]$ that studied grown and electron-irradiated $\mathrm{ZnO}$ samples. It has been shown experimentally that the dominant defect in electron-irradiated $\mathrm{n}-\mathrm{ZnO}$ samples is $\mathrm{V}_{\mathrm{Zn}}$, with the Fermi level located $0.2 \mathrm{eV}$ below the conduction band minima [14,19,20]. Neutral $\mathrm{V}_{\mathrm{O}}$ was also detected in these experiments. These results imply that charged $\mathrm{V}_{\mathrm{O}}$, if present, will only be in low concentrations below the detection limit due to their high formation energy as discussed above. Nevertheless, other experimental measurements have shown that native defects, and especially $\mathrm{V}_{\mathrm{O}}$ deep level defects, can contribute to the unintentional n-type conductivity of $\mathrm{ZnO}$ when present as complexes, but not as isolated native point defects [21]. On the other hand, $\mathrm{V}_{\mathrm{Zn}}$ has the lowest formation energy of all of the native defects in n-type $\mathrm{ZnO}$, while its formation energy in p-type $\mathrm{ZnO}$ is quite high [14]. This energy is low enough for $V_{Z n}^{2-}$ to occur in modestly doped $\mathrm{ZnO}$ and to act as a compensating center. Zinc vacancies usually introduce partially occupied states in the bandgap. These states are derived from the broken bonds of the oxygen's nearest four neighbors and lie close to the valence band minima. These states are partially filled and can accommodate an electron, causing $\mathrm{V}_{\mathrm{Zn}}$ to act as an acceptor. However, quantitative calculations showed that $\mathrm{V}_{\mathrm{Zn}}$ levels are deep acceptors. On the other hand, zinc vacancies are not believed to contribute to the p-type doping of $\mathrm{ZnO}$ due to the high formation energy of $\mathrm{V}_{\mathrm{Zn}}$ in p-type $\mathrm{ZnO}$ [14]. $\mathrm{V}_{\mathrm{Zn}}$ has been observed in many as-grown $\mathrm{n}-\mathrm{ZnO}$ materials and are more favorable when growth is performed in oxygen-rich conditions [14,19]. Zinc vacancies are situated $0.9 \mathrm{eV}$ above the valence band minima, and hence a transition from the conduction band (or from a shallow donor) would yield a luminescence around $2.4 \mathrm{eV}$. This corresponds to the green luminescence observed in $\mathrm{ZnO}$ samples grown by many techniques, appearing at 2.4-2.5 eV. Hence, $\mathrm{V}_{\mathrm{Zn}}$ is widely accepted to contribute to the broad band emission at this green wavelength, although $V_{O}$ was also suggested as early as 1954 [22] to be the source of this green emission (see discussion below). On the other hand, for n-type $\mathrm{ZnO}$, i.e., for a Fermi level close to the conduction band, interstitial zinc has high formation energy even under Zn-rich conditions, with a formation energy that reaches $6 \mathrm{eV}$. This implies that under equilibrium conditions, $\mathrm{Zn}_{\mathrm{i}}$ will be present in low concentrations and cannot contribute to the unintentional doping of $\mathrm{ZnO}$. Moreover, the formation energy of $\mathrm{Zn}_{i}^{2+}$ decreases rapidly as the Fermi level decreases toward the valence band minima. This implies that $\mathrm{Zn}_{\mathrm{i}}$ is a potential source of compensation in p-type $\mathrm{ZnO}$ [14]. The excess of oxygen in the $\mathrm{ZnO}$ lattice can be accommodated through the existence of oxygen interstitials, which can exist in electrically active or inactive forms. Electrically active $\mathrm{O}_{\mathrm{i}}$ occupies an octahedral site [14] 
and introduces states that can accept two electrons in the lower part of the $\mathrm{ZnO}$ bandgap. The result is a deep acceptor transition with states situated $0.72 \mathrm{eV}$ and $1.59 \mathrm{eV}$ above the valence band minima. The other form of $\mathrm{O}_{\mathrm{i}}$ is an electrically inactive configuration, which has quite high formation energies for both forms of $\mathrm{O}_{\mathrm{i}}$, except under extremely O-rich environments. This implies that $\mathrm{O}_{\mathrm{i}}$ is not expected to be present in high concentrations under equilibrium conditions. The remaining native defects are anti-sites. Zinc anti-sites or oxygen anti-sites consist of zinc or oxygen atoms sitting at the wrong lattice position. All calculations have agreed that $\mathrm{Zn}_{\mathrm{O}}$ forms shallow donors $[23,24]$. The final native defect is oxygen occupying an anti-site. Oxygen anti-sites can be created under non-equilibrium conditions, for example by irradiation or ion implantation [14]. Recent calculations indicated that $\mathrm{O}_{\mathrm{Zn}}$ is a deep acceptor level with two possible transitions situated $1.52 \mathrm{eV}$ and $1.77 \mathrm{eV}$ above the valence band minima. All of the native defects discussed above can exist in different charged states or in a neutral state, and the formation of complexes between native defects and other extrinsic species in $\mathrm{ZnO}$ has also been reported. As mentioned above, most of these native defects introduce deep levels at different positions in the bandgap, and hence a rather large number of luminescence lines with different energies can be observed. This explains why all of the visible colors have been experimentally observed in different $\mathrm{ZnO}$ samples.

The main known extrinsic deep-level defects in $\mathrm{ZnO}$ are $\mathrm{Li}, \mathrm{Cu}, \mathrm{Fe}, \mathrm{Mn}$, and $\mathrm{OH}$, each of which have been reported to emit at different wavelengths as discussed in more detail by Klingshirn et al. and Özgür et al. [6,11]. Different deep levels can produce different lines of the same color; one example of this is $\mathrm{ZnO}: \mathrm{Cu}$ and $\mathrm{ZnO}: \mathrm{Co}$, which emit different green colors [6]. This phenomenon is an additional source of the discrepancy in explaining the observed emission of $\mathrm{ZnO}$. Finally, hydrogen also plays an important role in the properties of the native defects. Hydrogen is not a deep level in $\mathrm{ZnO}$, but we mention it due to its important role as a donor. Unlike other semiconductors where hydrogen can be positive or negative, hydrogen in $\mathrm{ZnO}$ is always positive $\left(\mathrm{H}^{+}\right)$, i.e., it acts as a donor and possesses low ionization energy [25].

As mentioned above, the origin of the deep level emission band (DLE) has been controversial for decades. Below, we will briefly discuss some of the different opinions about the origin of the DLE based on different findings. The common bands observed in $\mathrm{ZnO}$ are green luminescence, yellow luminescence, and red luminescence DLE bands [11]. The green luminescence band, which appears at energies of 2.4-2.5 eV, is the most thoroughly investigated DLE band in $\mathrm{ZnO}$ and has been the subject of the most debate. Several studies have been published regarding the origin of this band, and they have used different experimental setups and different samples grown under various conditions. The green luminescence has been observed in samples grown by a variety of techniques. There may be multiple sources of this luminescence because different transitions can lead to quite similar luminescent emission wavelengths. Zinc vacancies, one of the most probable native defects in $\mathrm{ZnO}$, have been suggested by many authors to be the single source of this emission; see [26-28]. Oxygen vacancies have also been suggested by many authors [22,29-31]. In addition, zinc interstitials, oxygen interstitials, and other extrinsic deep levels including $\mathrm{Cu}$ have all been proposed as sources of the green luminescence emission in $\mathrm{ZnO}$. For more details, the reader is directed to [2,6,11] and the references therein. More recently, the green emission band has been explained as originating from more than one deep level defect. In this recent investigation, $V_{O}$ and $V_{Z n}$, which have different optical characteristics, were both found to contribute to the broad green luminescence band [32-34]. The yellow emission 
band that appears at $2.2 \mathrm{eV}$ was first observed in a Li-doped $\mathrm{ZnO}$ layer [9,35]. Li is located $0.8 \mathrm{eV}$ above the valence band and constitutes a deep acceptor level in $\mathrm{ZnO}$. Yellow emission has also been attributed to native deep level defects in $\mathrm{ZnO}$, namely to oxygen interstitials [36,37]. The yellow emission band was also observed with metastable behavior in undoped bulk $\mathrm{ZnO}$ [11]. Under irradiation by a He-Cd laser, the green luminescence band mentioned above was gradually bleached, and yellow emission emerged and saturated with an excitation density of $10^{-3} \mathrm{~W} / \mathrm{cm}^{2}$, implying that the associated deep level is present at a low density. The yellow emission band was recently observed in $\mathrm{ZnO}$ nanorods grown by low temperature $\left(90^{\circ} \mathrm{C}\right)$ chemical growth in different laboratories [38]. The origin of this band in these low-temperature grown samples was attributed to $\mathrm{O}_{\mathrm{i}}$ or the presence of $\mathrm{Li}$ impurities in the initial growth material. A $\mathrm{Zn}(\mathrm{OH})_{2}$ group attached to the surface of $\mathrm{ZnO}$ nanorods grown by chemical methods has also been proposed as a possible source of the yellow deep-level defect emission band in these samples [39]. Yellow emission has been observed in many different grown $\mathrm{ZnO}$ nanorods, and it was demonstrated that the emission can be replaced by the green and red bands upon post-growth annealing [39]. This was explained by the fact that upon proper post-growth annealing, the hydroxyl group can desorbs and hence modify the emission from that of the as-grown $\mathrm{ZnO}$ nanorods [39]. Orange, orange-red and red emission bands have also been observed in $\mathrm{ZnO}$ [39]. The orange emission, which is not very common in $\mathrm{ZnO}$, was proposed to be due to transitions related to oxygen interstitials [40], the orange-red emission was recently attributed to transitions associated with zinc vacancy complexes [41], and the red emission was proposed to be due to transitions associated with zinc interstitials [42]. Figure 1 shows a schematic diagram of the different energy levels (measured with respect to the conduction band edge) of the different deep-level defects reported by different groups. For completeness, the position of the extrinsic hydrogen energy level is also depicted, as this plays an important role in the n-type conductivity of $\mathrm{ZnO}$. The energy of the $\mathrm{V}_{\mathrm{O}} \mathrm{Zn}_{\mathrm{i}}$ cluster is also indicated. Table 1 also summarizes some of the different colors observed in recent reports and their associated deep-level defects.

Figure 1. Energy levels of the different deep level defects in $\mathrm{ZnO}$ reported in the literature by different groups: (a) ref [54]. (b) ref. [43].(c) ref. [56]. (d) ref. [44]. (e) ref. [25]. (f) ref. [14] and (g) ref. [9,35]. The + and - symbols represent charged deep levels. Three shallow levels are also shown, due to neutral oxygen vacancies, positively charged extrinsic hydrogen, and neutral zinc interstitials. In addition, the position of the deep level due to $\mathrm{V}_{\mathrm{O}} \mathrm{Zn}_{\mathrm{i}}$ clusters is indicated.

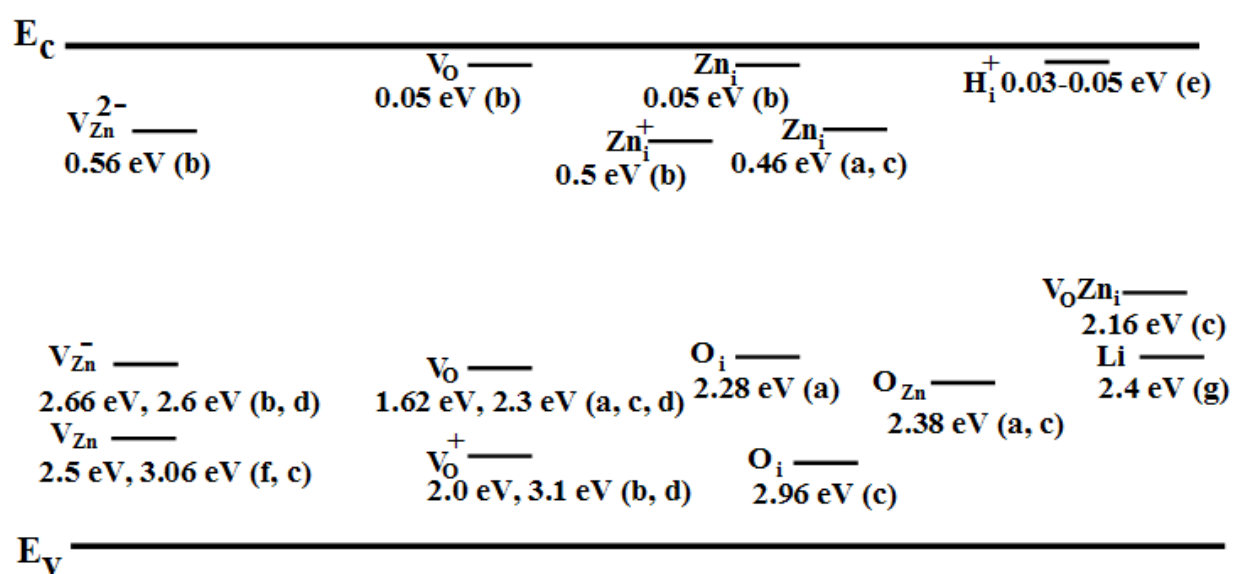


From the preceding discussion on the properties of the commonly reported deep level centers in $\mathrm{ZnO}$ and their associated possible transitions, it is clear that $\mathrm{ZnO}$ can emit luminescence over the entire visible region. Although no consensus has been reached regarding the origin of the different observed colors, partly due to the different defect configurations in different samples $[3,38]$, ZnO provides the potential for creating white light emitting diodes, especially considering the recent progress in the growth and reproducibility of $\mathrm{ZnO}$ nanostructures grown on a variety of other p-type substrates [2]. The development of low temperature chemical growth approaches as suitable techniques for large area synthesis of $\mathrm{ZnO}$ nanorods with excellent luminescence properties on any substrate opens up new possibilities for developing hybrid $\mathrm{ZnO}$ pn junctions. One of these hybrid junctions is a combination of $\mathrm{ZnO}$ nanorods and p-type semiconducting polymers. Below, we will report recent results obtained from different $\mathrm{ZnO}$ nanorods and nanotubes grown through different methods on $\mathrm{p}$-SiC, $\mathrm{p}-\mathrm{GaN}$, and ppolymer layers on flexible plastic, and we will report their use to fabricate white light emitting diodes (LEDs).

Table 1. Some recently reported lines emitted from $\mathrm{ZnO}$ and the proposed associated deep level defect(s) causing the emission. The conduction and valence bands are abbreviated in the usual way as C.B. and V.B., respectively.

\begin{tabular}{|c|c|}
\hline Emission color $(\mathrm{nm})$ & Proposed deep level transition \\
\hline Violet & $\mathrm{Zn}_{\mathrm{i}}$ to $\mathrm{V} . \mathrm{B}$. [3] \\
Blue & $\mathrm{Zn}_{\mathrm{i}}$ to $\mathrm{V}_{\mathrm{Zn}}$ or C.B. to $\mathrm{V}_{\mathrm{Zn}}[3,70]$ \\
Green & $\begin{array}{c}\text { C.B. to } \mathrm{V}_{\mathrm{O}} \text {, or to } \mathrm{V}_{\mathrm{Zn}} \text {, or C.B. to both } \mathrm{V}_{\mathrm{O}} \\
\text { and } \mathrm{V}_{\mathrm{Zn}}[67,32-34]\end{array}$ \\
Yellow & C.B. to $\mathrm{Li}$, or C.B. to $\mathrm{O}_{\mathrm{i}}[9,35-37]$ \\
Orange & C.B. to $\mathrm{O}_{\mathrm{i}}$ or $\mathrm{Zn}_{\mathrm{i}}$ to $\mathrm{O}_{\mathrm{i}}[3]$ \\
Red & $\left.\mathrm{Zn}_{\mathrm{i}}\right)[41]$ \\
\hline
\end{tabular}

\section{Results and Discussion}

This section presents some of our recent LEDs fabricated using $\mathrm{ZnO}$ nanorods and nanotubes grown by a high temperature evaporation method (vapor liquid solid technique) and by a low temperature method (aqueous chemical growth) at temperatures as low as $50{ }^{\circ} \mathrm{C}$. Figure 2 presents a diagram showing the structure of all of the fabricated white LEDs. As shown in the figure, all white LEDs were fabricated with $\mathrm{ZnO}$ nanorods or nanotubes grown on top of the different p-type substrates. 
Figure 2. A schematic diagram of $\mathrm{n}-\mathrm{ZnO}$ nanostructures on different p-type substrates.

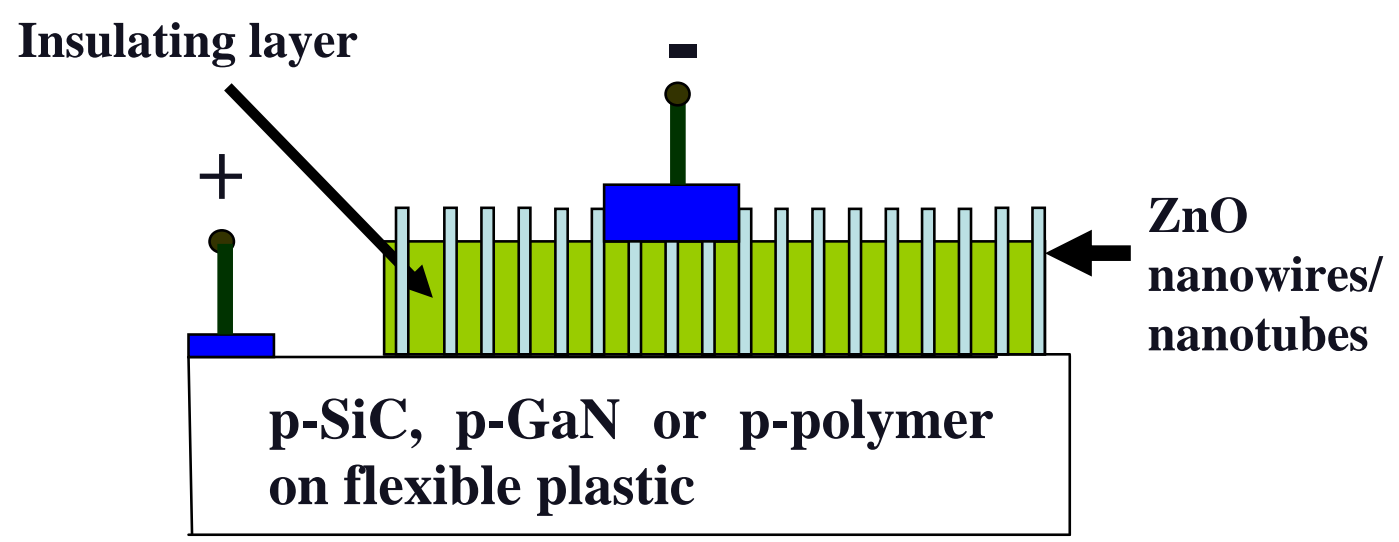

\section{1. $n$-ZnO nanorods/4H-p-SiC LEDs}

$\mathrm{ZnO}$ nanorods were grown using the vapor liquid solid (VLS) high temperature technique on a 4H$\mathrm{p}$-SiC epitaxial layer, for the purpose of forming a pn heterojunction (described below). The grown nanorods were found to be aligned vertically and the nanorod length varied within the range 1.9-2.2 $\mu \mathrm{m}$, as shown in the scanning electron microscope image (SEM) in Figure 3.

Figure 3. (Left) A typical SEM image of ZnO nanorods grown by the VLS technique on a 4H-p-SiC epitaxial layer. (Right) Typical room temperature I-V characteristics obtained from the LED fabricated with $\mathrm{n}-\mathrm{ZnO}$ nanorods/4H-p-SiC.
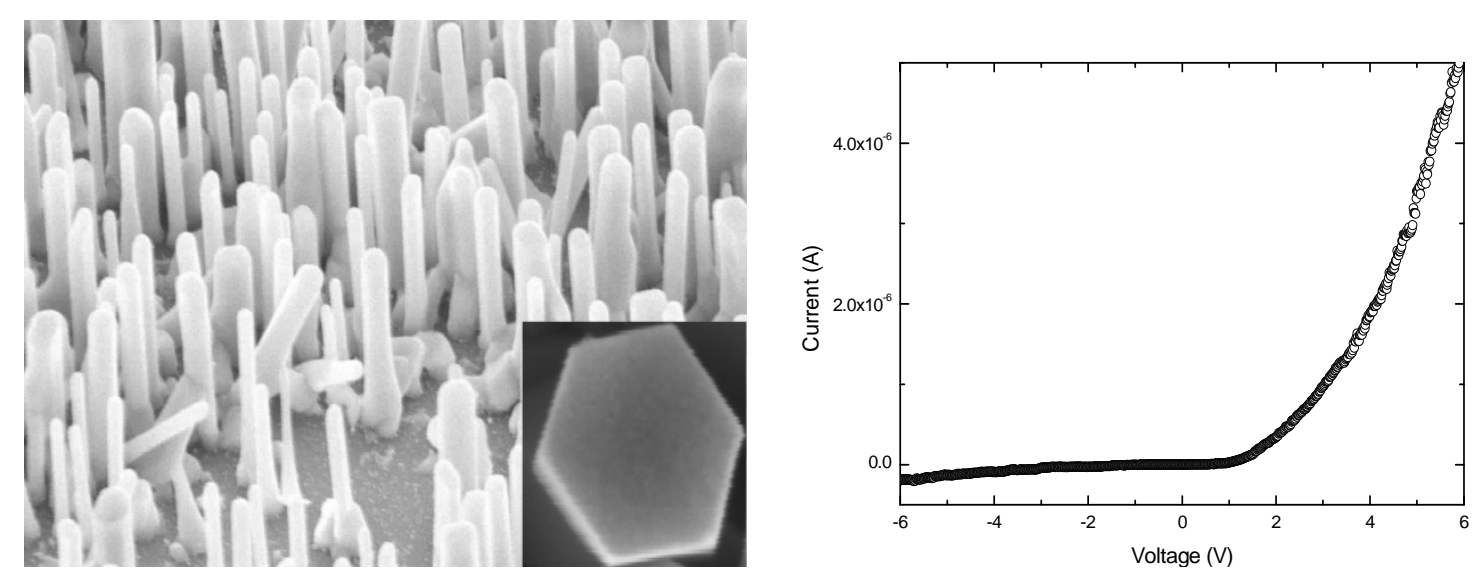

The optical properties of grown $\mathrm{ZnO}$ nanorods on the $4 \mathrm{H}-\mathrm{SiC}$ sample were investigated using room temperature photoluminescence (PL), and the result (not shown here) indicates a sharp ultra-violet (UV) emission line around $380 \mathrm{~nm}$ due to the bandgap edge, as well as broad green luminescence bands centered around $530 \mathrm{~nm}$ and covering a large range of the visible spectrum. The observation of sharp UV emission indicates that the $\mathrm{ZnO}$ nanorods had a high crystal quality.

Figure 3 shows the resulting typical current-voltage characteristics of the $\mathrm{ZnO}$ nanorods/4H-p-SiC heterojunctions analyzed using standard thermoionic emission theory. According to this theory, the current in such a device can be expressed as 


$$
I=I_{S}\left[\exp \left(\frac{q V}{n k_{B} T}\right)-1\right],
$$

where $I_{s}$ is the saturation current, $k_{B}$ is the Boltzmann constant, $T$ is the absolute temperature, $q$ is the elementary electric charge, $\mathrm{V}$ is the applied voltage, and $\mathrm{n}$ is the ideality factor. The ideality factor in Eq. (2) was found to be in the range of 3-4 for the investigated diode. A higher ideality factor indicates that the transport mechanism is no longer dominated by thermionic emission. Non-ideal behavior is often attributed to variations in the interface composition and to other current transport mechanisms provided by other defect states in the band gap of the semiconductor such as structural defects, surface contamination, barrier tunneling, or generation and recombination in the space charge region $[45,46]$. To understand which mechanisms influence the junction behavior, the I-V characteristics of the device are studied on a log-log scale. A log-log plot of the I-V data at RT is shown in Figure 4, and it demonstrates that the current transport mechanism exhibits three different regions. The current in region 1 follows a linear dependence, i.e., $\mathrm{I} \sim \mathrm{V}$. This indicates that transport is dominated by tunneling at low voltages. The boundary for this region was determined to be $0.03 \mathrm{~V}$. In region $2(0.04-1 \mathrm{~V})$, the current increases exponentially, $\mathrm{I} \sim \exp (\mathrm{cV})$. The ideality factor (3-4) is determined in this region, and the dominant transport mechanism is recombination-tunneling. Finally, above $1 \mathrm{~V}$ (region 3) the current follows a power law $\left(\mathrm{I} \sim \mathrm{V}^{2.5}\right)$, indicating a space-charge limited transport mechanism. The space charge limited current (SCLC) region observed in the present study has also been reported in different $\mathrm{n}-\mathrm{ZnO}$ nanorods/p-Si heterojunction LEDs [47-49].

Figure 4. Log-log plot of the I-V characteristics of the 4H-p-SiC/n-ZnO heterojunction LED.

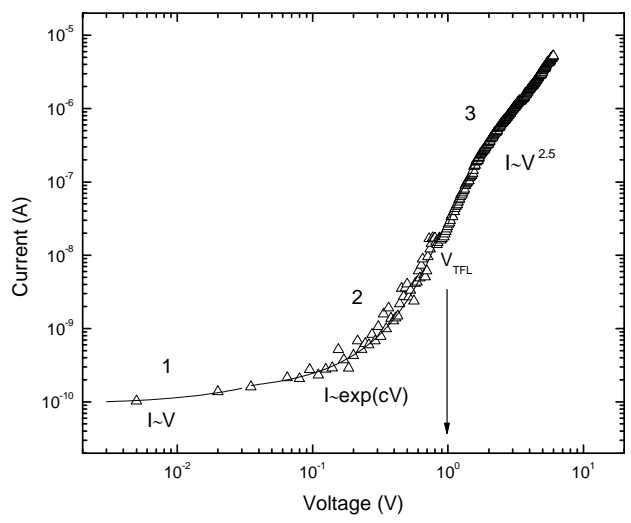

Lampert and Mark [50] have developed the single carrier SCLC model in the presence of a trap above the Fermi level. According to this model, at an applied voltage of $\mathrm{V}>\mathrm{V}_{\mathrm{TFL}}$ (TFL indicates the trap filled limit) all of the trap levels are filled, the conduction becomes space charge limited, and the current follows the Mott and Gurney SCLC expression [51]. The trap filled limit voltage $\mathrm{V}_{\mathrm{TFL}}$ is given as [50]:

$$
V_{T F L}=\frac{N_{t} q d^{2}}{2 \varepsilon \varepsilon_{0}}
$$


where $\mathrm{N}_{\mathrm{t}}$ is the concentration of unoccupied states (trap concentration) located approximately at the estimated effective Fermi level. The effective carrier concentration $n_{o}$ in the active region is given by the expression:

$$
\frac{J\left(2 V_{T F L}\right)}{J\left(V_{T F L}\right)} \approx \frac{N_{t}}{n_{0}}
$$

where $\mathrm{J}\left(\mathrm{V}_{\mathrm{TFL}}\right)$ is the current density at $\mathrm{V}_{\mathrm{TFL}}$ and $\mathrm{J}\left(2 \mathrm{~V}_{\mathrm{TFL}}\right)$ is the current density at a voltage of twice $\mathrm{V}_{\mathrm{TFL}}$. The position of the effective Fermi level (quasi-Fermi level) can be estimated from the calculated value of $n_{0}$. Deep level parameters were calculated from the experimental $V_{T F L}$ at RT. The depletion region thickness $(1.2 \mu \mathrm{m})$ at zero bias capacitance was used as the active layer thickness in these calculations. The values of $\mathrm{n}_{\mathrm{o}}, \mathrm{N}_{\mathrm{t}}$, and the location of the deep level states (traps) below the conduction band were determined to be $3.4 \times 10^{17} \mathrm{~cm}^{-3}, 4.4 \times 10^{18} \mathrm{~cm}^{-3}$, and $\sim 0.24 \pm 0.02 \mathrm{eV}$, respectively. These observed deep level states are in agreement with the reported data for the zinc interstitial $\left(\mathrm{Zn}_{\mathrm{i}}\right)$ level, which is theoretically located $0.22 \mathrm{eV}$ below the conduction band [52]. Violet emission has recently been reported to originate from $\mathrm{Zn}_{\mathrm{i}}$ [3]. In addition, according to calculations based on the full potential linear muffin-tin orbital method, the transition energy from the $\mathrm{Zn}_{\mathrm{i}}$ level to the valence band in $\mathrm{ZnO}$ corresponds to $3.1 \mathrm{eV}$ [53]. This agrees well with our experimental results. The extracted transition energy from the observed trap $\left(\mathrm{Zn}_{\mathrm{i}}\right)$ to the valence band is $3.13 \pm 0.02 \mathrm{eV}$.

Figure 5. Room temperature EL spectrum of the 4H-p-SiC/n-ZnO heterojunction LED, revealing broad emission covering the entire visible spectrum.

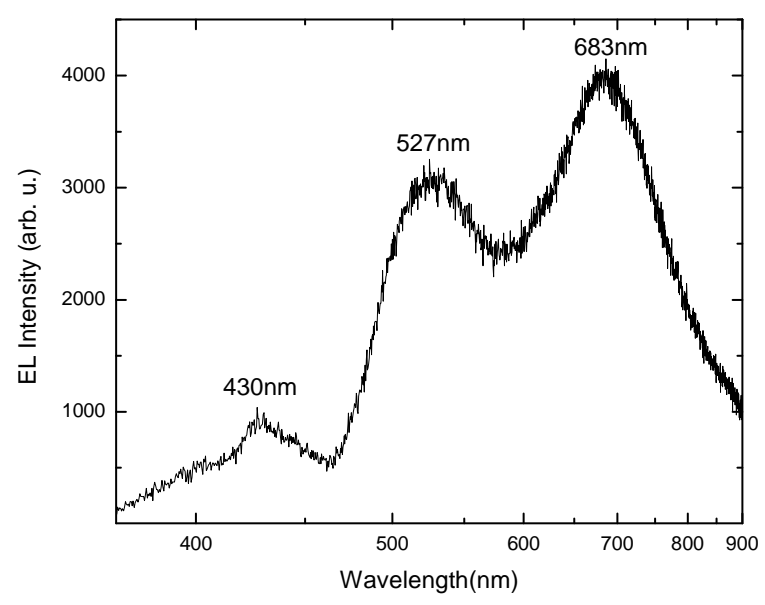

The EL measurement of the ZnO-based heterojunction was carried out using a photomultiplier detector at room temperature. Figure 5 shows the corresponding EL spectrum, indicating three peaks at $430 \mathrm{~nm}$ (violet), $527 \mathrm{~nm}$ (green) and $683 \mathrm{~nm}$ (red). Several groups have reported that different defect centers in $\mathrm{ZnO}$ are responsible for the blue, green and red emissions [3,54]. Leiter et al. observed a broad green band centered at $2.45 \mathrm{eV}$ and assigned it to the oxygen vacancy (Vo) [55]. The $2.38 \mathrm{eV}$ green emission has been attributed to the oxygen antisite $\left(\mathrm{O}_{\mathrm{Zn}}\right)$ on theoretical grounds [56]. There is still controversy in the literature about the origin of the luminescence centers observed in $\mathrm{ZnO}$ materials [57]. Recent studies have demonstrated that the green emission at $533 \mathrm{~nm}$ is related to 
oxygen vacancies $\mathrm{V}_{\mathrm{O}}$, and the red emission at $683 \mathrm{~nm}$ is related to zinc vacancies or excess oxygen $[3,52]$. Our EL spectra demonstrate peaks at $527 \mathrm{~nm}$ and $683 \mathrm{~nm}$, and these are due to $\mathrm{V}_{\mathrm{O}}$ and $\mathrm{V}_{\mathrm{Zn}}$ in the $\mathrm{ZnO}$ nanorods, respectively [3,33]. The violet emission at $430 \mathrm{~nm}$ is due to the interstitial zinc $\left(\mathrm{Zn}_{\mathrm{i}}\right)$ [3]. It was recently reported that the violet emission corresponds to $\mathrm{Zn}_{\mathrm{i}}$ and the transition involving $\mathrm{V}_{\mathrm{Zn}}$ would result in blue emission $[3,39,58]$. It has also been reported that in wide band gap semiconductors, the broad band luminescence is related to transitions from donor states to deep acceptor states [59].

Cathodoluminescence (CL) spectroscopy was performed to obtain detailed emission information and to explain the origin of specific emissions from specific areas. The cathodoluminescence spectroscopy technique involves an incident electron beam of an energy that produces free electronhole pair recombination across the bandgap or between deep levels and the band edges. The CL penetration depth increases with increasing beam energy, as determined by the energy-range relationships for energy loss within a solid [60,61]. CL signals from different depths within the bandgap of the material can be excited, and the average depth distribution of the luminescence can thus be determined. The acceleration voltage for this study was varied from 10 to $30 \mathrm{kV}$, which corresponds to maximum penetration depths of $0.4-2.16 \mu \mathrm{m}$, as calculated from the Kanaya-Okayama model [61].

Figure 6. (left) Depth-dependent cathodoluminescence (CL) spectra of ZnO NRs, taken with a spot size of $50 \mathrm{~nm}$ at room temperature, at different accelerating voltages and a constant current of $56 \mathrm{pA}$. (right) The emission intensity ratio of the near band edge and green bands as a function of penetration depth.
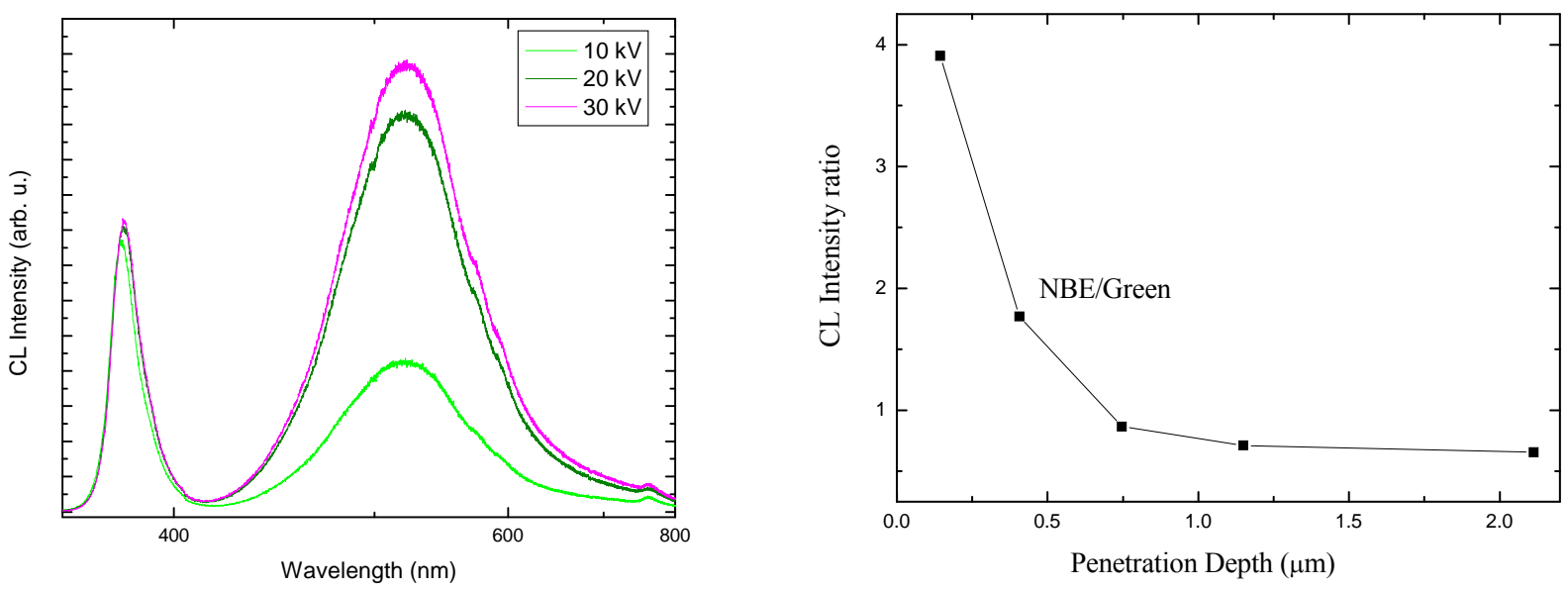

To understand the emission properties of $\mathrm{ZnO}$ nanorods, it is necessary to clarify the effect of electron beam conditions on the CL measurement. The accelerating voltage is considered to be the main parameter that affects the electron beam [62]. Therefore, depth-dependent CL spectra were collected. Figure 6 (left) shows the RT-CL spectra at different accelerating voltages $(10-30 \mathrm{kV})$ for a constant current of $56 \mathrm{pA}$. The number of excited carriers is assumed to be proportional to the accelerating voltage. The CL spectra exhibit NBE emission at $380 \mathrm{~nm}$, which is related to the direct recombination of photon-generated charge carriers (excitonic emission), a green band centered at 
$524 \mathrm{~nm}$, and red emission at $750 \mathrm{~nm}$. Note that all of the CL spectra are red shifted because the sample was heated by electron bombardment.

The penetration depth, which is related to the rate of electron-hole pair creation, varies with the incident electron accelerating voltage, with values of $0.4,1.14$ and $2.16 \mu \mathrm{m}$ for accelerating voltages of 10,20 and $30 \mathrm{kV}$, respectively. Thus, an electron acceleration voltage of $20 \mathrm{kV}$ corresponds to approximately $1 \mu \mathrm{m}$ of penetration depth [60]. The RT-CL spectra exhibit a constant NBE as the accelerating voltage changes, while the green emission varies. This indicates that the native point defect concentration might vary with depth. When the accelerating voltage is increased, the electron beam is expected to penetrate deeper into the nanorods and excite more electron-hole pairs near and below the penetration depth. Because of this, more emission centers will be excited by the electron bombardment. In bulk $\mathrm{ZnO}$ and thin $\mathrm{ZnO}$ films, UV emission from $\mathrm{ZnO}$ can be internally reabsorbed by the crystal within a $1 \mu \mathrm{m}$ range [63]. However, this reabsorbed UV emission can excite defect states in the material, resulting in the green emission. Thus, part of the UV emission may contribute to the enhancement of the green emission [64]. The differences and variations in the size of the nanostructures also contribute to the emission intensities. A luminescence spectrum usually represents the optical characteristics of all of the nanostructures inside the probed area, and due to inhomogeneities among the nanostructures, the spectrum can be considered an average luminescence [65]. Remarkably, the ratio of the NBE to the green intensity, which is used as an indicator of nanorod quality, decreases with penetration depth over the entire length of these nanorods. As a result, the right panel of Figure 6 indicates that there are more deep defects at the roots of the $\mathrm{ZnO}$ nanorods than in their upper parts. Willander et al. demonstrated through a HR-TEM study that $\mathrm{ZnO}$ nanorods have more structural defects at the interface between the $\mathrm{ZnO}$ nanorods and the substrate than at the top of the nanorod [2]. Chien-Lin et al. reported that the NBE and green are emitted separately from two opposite halves of the nano-rods [66]. CL spectroscopy gives in-depth information about radiative defects. Using this technique on our samples together with results from others [2,66] indicates that there are more deep defects (radiative defects) at the roots of the $\mathrm{ZnO}$ nanorods. Nevertheless, it has also been shown that depletion layers at surfaces or grain boundaries might alter the defect charge states and hence modify the resulting emission [67]. This effect can also contribute to the observed variation in green emission with depth [67]. To fully understand the origin of the correlation between luminescence and transport characteristics, more systematic investigation of the samples is necessary. The inhomogeneities observed among $\mathrm{ZnO}$ nanostructures can be attributed to fluctuations during the growth and formation of the nanostructures. Investigation of inhomogeneities among $\mathrm{ZnO}$ nanostructures grown by different methods can shed some light on the fundamental growth mechanisms and possible improvements.

\section{2. $n$-ZnO nanotubes/p-GaN LEDs}

Nanotubes, or hollow nanorods, possess a much larger surface to volume ratio than nanorods. The increased surface area implies that the concentration of surface defects would be expected to increase. Surface states, which lead to deep radiative levels, can easily be manipulated by post-growth processing. This manipulation can lead to enhancement or changes in the nature of complex defects adsorbed to the surface, and hence, nanotubes add more degrees of freedom in LED design. 
Whispering gallery modes also may enhance the optical characteristics of $\mathrm{ZnO}$ nanotubes compared to nanorods [68]. Hence, the use of $\mathrm{ZnO}$ nanotubes will be expected to yield interesting results, with the possibility of manipulating the emission from surface defects. We have developed a technique to synthesize $\mathrm{ZnO}$ nanotubes with very high yield [68]. Figure 7(a) shows an SEM image of $\mathrm{ZnO}$ nanotubes with diameters between 100-150 nm, lengths from 1 to 2 microns, and wall thicknesses of 20-35 nm, showing epitaxial orientation almost normal to the substrate. It is clear from the image that these $\mathrm{ZnO}$ nanotubes are hollow with $100 \%$ yield. Transmission electron microscopy (TEM) was further used to confirm the tubular structure and to measure the etching depth of the $\mathrm{ZnO}$ nanotubes, which was intentionally kept within the range of 700-900 $\mathrm{nm}$ to protect the hetero-junction between the nanotubes and substrate, as seen in Figure 7(b). A high resolution TEM image (Figure 7(c)) shows that the $\mathrm{ZnO}$ nanotubes are single crystalline and the orientation of the nanotube in the microscope demonstrated that the growth direction of the $\mathrm{ZnO}$ nanotube is along the c-axis of the wurtzite structure. The etching mechanism is related to the wurtzite crystal structure of $\mathrm{ZnO}$ nanorods and relies on the difference in stability of the polar $(0001)$ and non-polar $\left(10 \overline{1}_{0}\right)$ planes. The structural stability of the polar planes of the nanorods is important for the high etching rate by the adsorption of chloride ions along the polar direction instead of the non-polar direction [69].

Figure 7. (a) SEM image of $\mathrm{ZnO}$ nanotubes grown on $\mathrm{p}-\mathrm{GaN}$. (b) Low resolution TEM image of a single nanotube, showing the depth of etching inside the nanotube. (c) High resolution TEM image of a single $\mathrm{ZnO}$ nanotube.

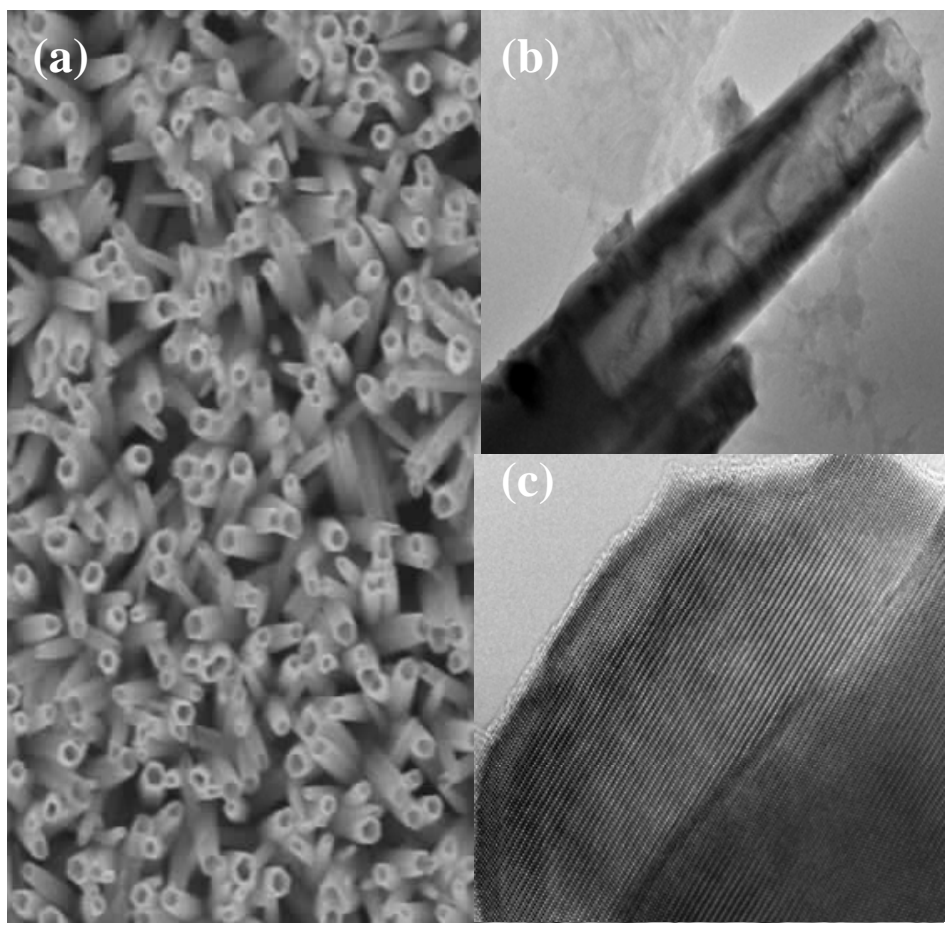

Figure 8(a) displays the room temperature photoluminescence (PL) of the $\mathrm{ZnO}$ nanotubes, revealing two emission bands: UV and visible. The former, relatively weak peak centered at $389 \mathrm{~nm}$ can be attributed to the radiative recombination of free excitons, while the visible broad band emission centered at $596 \mathrm{~nm}$ may be related to deep level defects. The reason for the broad visible band is that 
$\mathrm{ZnO}$ nanotubes have a large surface to volume ratio and a high porosity. The etching process used in nanorod fabrication is also an important source of surface defect formation. The deep level emission is known to be related to a variety of intrinsic $\left(V_{\mathrm{Zn}}, V_{\mathrm{O}}\right.$, or $\left.\mathrm{Zn}_{\mathrm{i}}\right)$ and extrinsic (acceptor) defects [6]. The electroluminescence (EL) characteristics of the $\mathrm{n}-\mathrm{ZnO}$ nanotubes $/ \mathrm{p}-\mathrm{GaN}$ heterostructure LEDs were studied under a forward bias current.

Figure 8. (a) Room temperature PL spectrum of $\mathrm{ZnO}$ nanotubes grown on GaN. (b) The corresponding electroluminescence spectrum obtained from the same $\mathrm{ZnO}$ nanotubes $/ \mathrm{p}$ GaN LED. The inset displays a digital photograph showing the light emission.
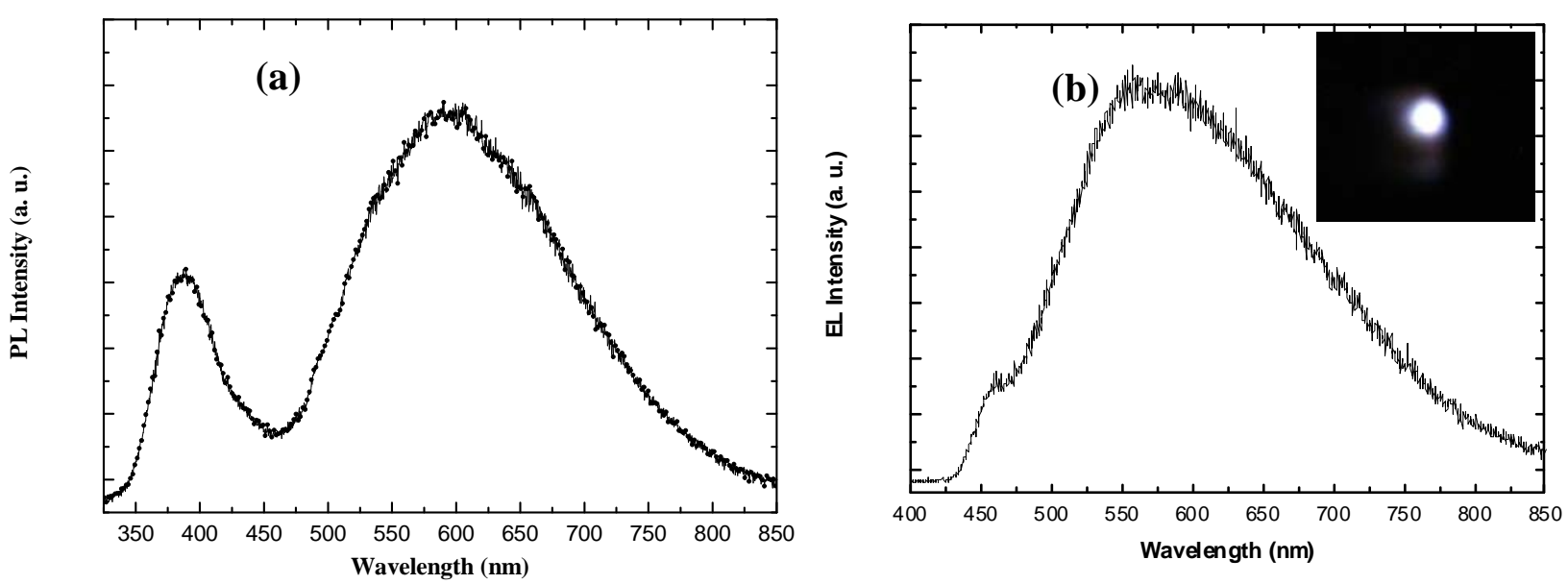

The EL spectrum shows a large broad-band emission and relatively low blue and violet emission peaks centered around $570 \mathrm{~nm}$ and $450 \mathrm{~nm}$, respectively, as shown in Figure 8(b). The emission over the broad band covering $475-800 \mathrm{~nm}$ is attributed to the injection of the holes from $\mathrm{p}-\mathrm{GaN}$ toward the $\mathrm{ZnO}$ nanotubes and their recombination with defect states in the $\mathrm{ZnO}$ nanotubes. The injected forward current activates the more radiative recombination centers in $\mathrm{ZnO}$ nanotubes, which enhances the brightness of the white light emission, along with the large number of surface defect states and bulk defects in the $\mathrm{ZnO}$ nanotubes [68]. The origin of the blue-violet peak centered at $450 \mathrm{~nm}$ is still controversial, with possible sources of the transition from zinc interstitial to zinc vacancy [3,70] and the radiative recombination related to deep $\mathrm{Mg}$ acceptor levels [71,72].

\section{3. n-ZnO nanorods/p-polymer hybrid LEDs}

As mentioned above, $\mathrm{ZnO}$ possesses the property of self-organized growth. This property has made it possible to grow $\mathrm{ZnO}$ nanostructures with device-quality crystals on a variety of substrates, even those of an amorphous nature [2]. Moreover, the possibility of low temperature aqueous chemical growth enables the growth of $\mathrm{ZnO}$ nanorods with excellent luminescent properties on large area substrates. This possibility suggests the combination of $\mathrm{ZnO}$ nanorods and organic polymer electrodes to form a hybrid lighting technology that avoids the problems associated with p-type $\mathrm{ZnO}$. These hybrid organic-inorganic light emitting diodes have recently been suggested, and the electroluminescence of these materials has been reported by different groups [73-77]. In our previously presented organic-ZnO nanorod hybrid light emitting diodes, we grew the nanorods on 
glass substrates at a temperature of $95^{\circ} \mathrm{C}[75,76]$. PEDOT:PSS was first spin-coated onto the glass and flowed by the p-type-polymer(s) layer(s). The output emission intensity and wavelength of these materials can be modified by engineering the p-type polymer layer sequence. We have designed different multi-layer p-type polymers with the strategy of having a divided hole barrier to improve the current and hence increase the output intensity of light emitted from this organic-inorganic hybrid structure [75]. The hole transport in the organic electrode and the viscosity of the polymer were considered, and pure and blended configurations were investigated [75]. We also demonstrated that it was possible to optimize the electrical and electro-optical emissions of this hybrid LED by inserting a proper hole barrier divider between the p-type polymer and the $\mathrm{ZnO}$ nanorods [76]. Here, we present our most recent results from an even lower temperature hybrid LED on flexible plastic. We have been able to grow $\mathrm{ZnO}$ with good structural and excellent luminescent properties at $50{ }^{\circ} \mathrm{C}$ on flexible plastic, and this material emits white luminescence as shown below.

Figure 9. Typical SEM image showing $\mathrm{ZnO}$ nanorods grown at $50{ }^{\circ} \mathrm{C}$. These $\mathrm{ZnO}$ nanorods were grown on a flexible plastic substrate using the aqueous chemical approach.

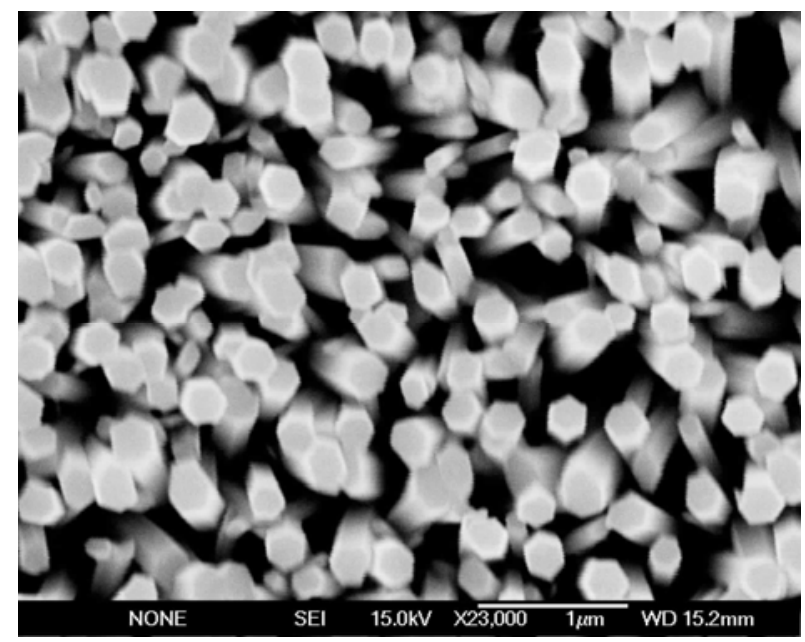

Growth of $\mathrm{ZnO}$ nanorods on flexible substrates was performed at temperatures as low as $50{ }^{\circ} \mathrm{C}$; the details of the growth procedures will be discussed elsewhere. The as-deposited $\mathrm{ZnO}$ nanorods demonstrate a c-axis preferential orientation, as can be seen in the SEM micrograph in Figure 9. This image clearly shows well-aligned nanorods with hexagonal tips, diameters of about $200 \mathrm{~nm}$ and an average length of about $1.2 \mu \mathrm{m}$. X-ray diffraction analysis revealed that c-axially oriented $\mathrm{ZnO}$ nanorods were achieved because the 002 peak dominated the XRD spectrum (not shown here). $\mathrm{ZnO}$ nanorods grown at $50{ }^{\circ} \mathrm{C}$ were combined with p-type polymers to fabricate hybrid LEDs. Before the processing of the device, room temperature PL was performed on the polymers on the flexible substrate and was performed again after the low temperature growth of the $\mathrm{ZnO}$ nanorods. The results are shown in Figure 10(a-b). The device was constructed using the well-known PFO p-type polymer, a blue light emitter. The polymer layer sequence was as follows: first PEDOT:PSS was deposited onto the flexible plastic, then TFB was spin-coated, followed by the PFO. The TFB was inserted to divide the relatively large hole barrier between the PFO and the PEDOT:PSS. Figure 10a shows the room temperature PL spectrum of the PFO/TFB polymer multi-layers spin-coated onto the flexible substrate. 
As expected, blue emission due to the PFO is observed in the PL spectrum, as shown in Figure 10a. Figure $10 \mathrm{~b}$ shows the $\mathrm{PL}$ of the $\mathrm{ZnO}$ nanorods grown on top of the polymer layers on flexible plastic. As clearly indicated by the PL, intense near band emission band at $390 \mathrm{~nm}$ demonstrates radiative recombination between electrons from the $\mathrm{ZnO}$ conduction band with holes in the valence band or a defect level close to it. Moreover, defect-related transitions are apparently observed in the PL spectrum, where a broad band around $520 \mathrm{~nm}$ (green band) as well as a third broad peak at $660 \mathrm{~nm}$ (orange red band) were both observed. The origin of these defects' radiative transitions was discussed above; they can be attributed to oxygen and zinc vacancies and oxygen interstitial atoms, respectively $[3,33]$. The as-deposited $\mathrm{ZnO}$ nanorods grown at low temperature on a flexible substrate were then used to fabricate an LED.

Figure 10. (a) Room temperature PL spectrum obtained from p-type polymer(s) layers spin-coated onto flexible plastic. (b) The corresponding room temperature PL spectrum after the low-temperature growth of $\mathrm{ZnO}$ nanorods. The lower curve represents the $\mathrm{PL}$ presented in part (a) of the figure to allow for a comparison of intensities.
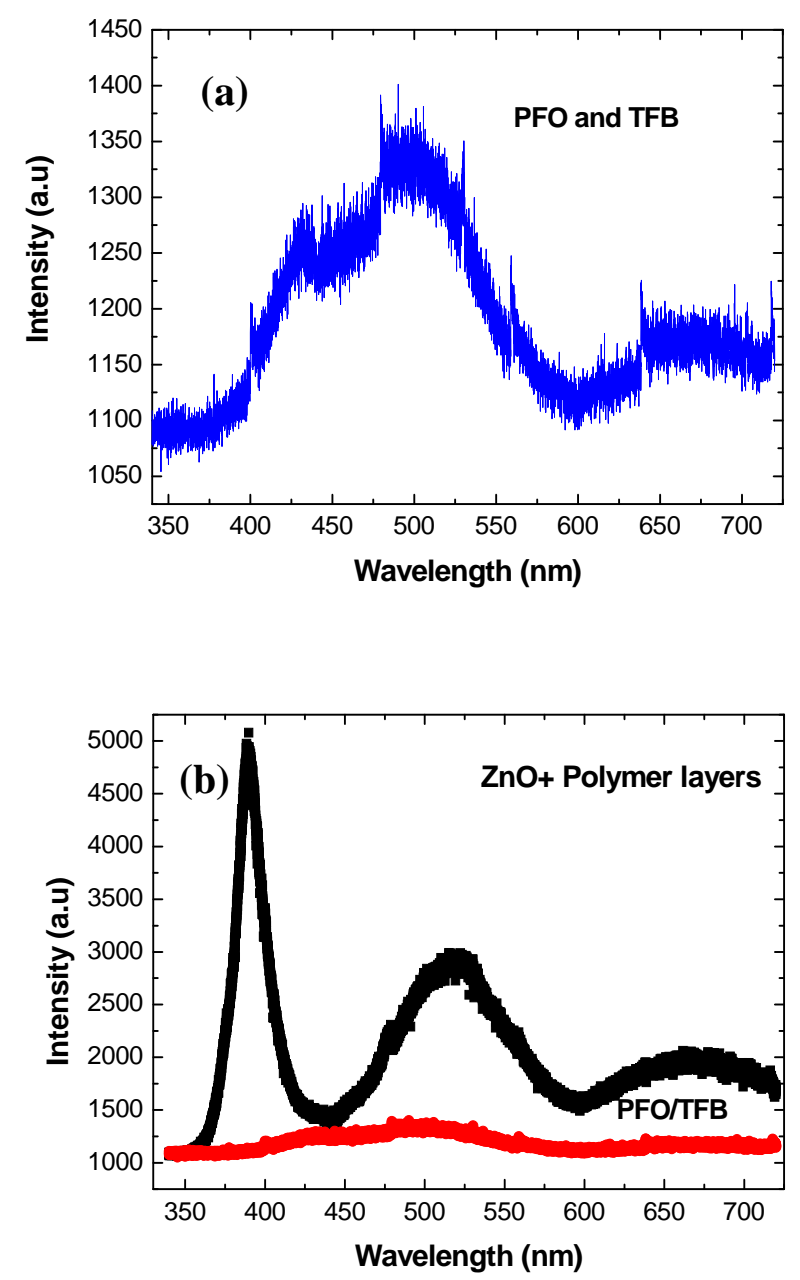

The electrical behavior of the hybrid LEDs obtained using the $\mathrm{ZnO}$ nanorods grown at $50{ }^{\circ} \mathrm{C}$ was investigated, and rectifying behavior was observed. Figure 11(a) shows typical I-V characteristics, revealing rectification behavior with a turn-on voltage as low as $2.4 \mathrm{~V}$. Light emission was detected at 
current levels of about $0.2 \mathrm{~mA}$. The diode was stored for a few weeks (12 weeks) and investigated again, and no degradation was observed. Figure 11(b) shows the electroluminescence spectrum of this hybrid organic-inorganic LED, with a broad band covering emissions from just above $400 \mathrm{~nm}$ and up to nearly $700 \mathrm{~nm}$, with a peak at around $560 \mathrm{~nm}$. As the next step in the construction of a functional LED, we are now examining the light quality and output power of this hybrid LED.

Figure 11. (a) I-V characteristics of the hybrid LED obtained using $\mathrm{ZnO}$ nanorods grown at $50{ }^{\circ} \mathrm{C}$. (b) Electroluminence spectrum obtained from the hybrid LED revealing white luminescence covering the entire visible range (from above $400 \mathrm{~nm}$ and up to nearly 700 $\mathrm{nm}$ ), resulting from the combination of the $\mathrm{PFO} / \mathrm{TFB}$ and the low-temperature grown $\mathrm{ZnO}$ nanorods. The PFO emission at $450 \mathrm{~nm}$ appears in the EL as a shoulder.
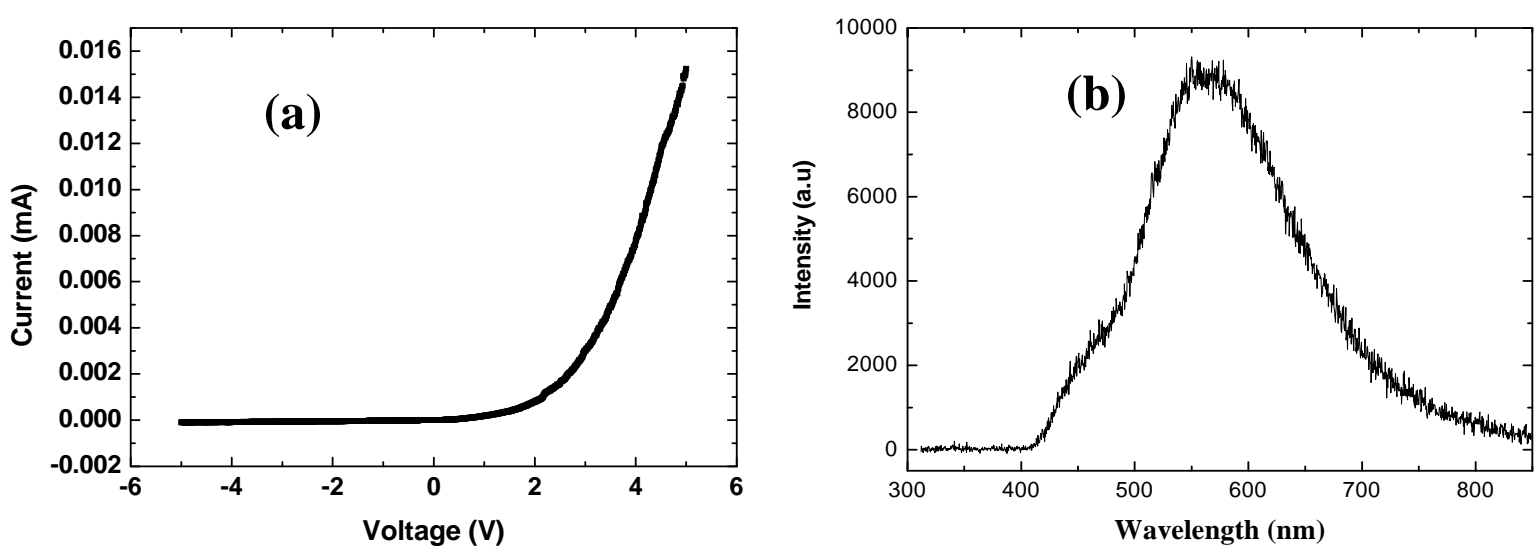

\section{4. $n$-ZnO nanorods and external p-type electrodes}

Although $\mathrm{ZnO}$ has been studied for many decades now, no commercial electro-optical components (LEDs or lasers) have been developed utilizing this excellent luminescent material. The main reason for this is the lack of a stable, reproducible p-type doping scenario for $\mathrm{ZnO}$ material. Many attempts have been made to achieve hetero-epitaxy of $\mathrm{ZnO}$ thin films on different p-type substrates. Nevertheless, none of these attempts have resulted in device-quality $\mathrm{ZnO}$ thin film/p-type heterostructures. As mentioned above, $\mathrm{ZnO}$ possesses the property of self-organized growth, which is beneficial for the growth of $\mathrm{ZnO}$ nanostructures. According to results published during recent years and shown above, $\mathrm{ZnO}$ nanostructures, especially nanorods and nanotubes can easily be grown on a variety of substrates $[2,78]$. Crystalline as well as amorphous substrates have been demonstrated to be good platforms for the growth of device-quality $\mathrm{ZnO}$ nanorods/nanotubes that form high-quality heterojunctions with different p-type substrates. In addition, these $\mathrm{ZnO}$ nanorods-nanotubes/p-type substrates have shown to yield white electroluminescence due to emission from the native deep levels that emit over the entire visible range as discussed above. With the use of techniques like aqueous chemical growth (see below), the large area growth of $\mathrm{ZnO}$ nano-structures can easily be achieved on a variety of substrates. The use of aqueous chemical growth of $\mathrm{ZnO}$ nanorods on a p-type polymer on flexible plastic substrates seems to be the best choice for the realization of commercial white light emitting diodes due to the cost and ease of use of large area substrates, and the possibility of integrating the flexible plastic with available lighting armature technology (glass bulbs and tubes). 
However, the growth parameters must first be optimized to obtain white light with a high color rendering index (CRI) and an acceptable light output efficiency (50 lumen/Watt). Moreover, the longterm stability must be investigated before these commercial products can be made available.

\section{Experimental Section}

The results presented above in Section 3 were achieved using $\mathrm{ZnO}$ nanorods/nanotubes synthesized using two different techniques, the vapor liquid solid (VLS) technique performed at high temperatures $\left(>850^{\circ} \mathrm{C}\right)$ and low-temperature $\left(<100^{\circ} \mathrm{C}\right)$ aqueous chemical growth (ACG). Below, we explain these two techniques and briefly describe the processing of the presented LEDs.

VLS based processes have been widely used for the growth of various nanostructures since the first demonstration in 1964 by Wagner and Ellis [79]. The VLS process can be divided into two steps: the formation of a small liquid droplet and the nucleation and growth of the nanorods. Generally, the growth of $\mathrm{ZnO}$ nanorods is accomplished by employing metal clusters as catalysts. The metal can be chosen rationally using the phase diagram on the basis of the solubility of the nanorods' component elements in the liquid phase. The growth direction and diameter of the $\mathrm{ZnO}$ nanorods during the growth process are highly dependent on the metal droplet, which is composed of the metal catalyst and the nanorod material. Au is the most commonly used catalyst for the growth of $\mathrm{ZnO}$ nanorods when using the VLS growth method [80] because Au has the ability to form a eutectic mixture with the $\mathrm{ZnO}$ material at temperatures far below the melting point of $\mathrm{ZnO}$. Other metals such as tin have also been successfully used to synthesize high-quality $\mathrm{ZnO}$ nanorods [5]. The method of thermal evaporation was used to grow $\mathrm{ZnO}$ nanorods on a $\mathrm{p}$-SiC substrate using $\mathrm{Au}$ as a catalyst in a flat quartz oven. Figure 12 shows a typical experimental setup used for the growth of $\mathrm{ZnO}$ nanorods. A thin layer of $\mathrm{Au}$ (3-5 nm) was first deposited onto the p-SiC substrate. High-purity (99.9\%) commercial ZnO powder was used as the main source material. The high purity $\mathrm{ZnO}$ powder was mixed with high purity (99.9\%) graphite at a 1:1 ratio, and the mixture was placed in a quartz boat. The mixed powder was vaporized at elevated temperatures $\left(>890^{\circ} \mathrm{C}\right)$ and $\mathrm{Zn}$ condensed onto the substrate containing the $\mathrm{Au}$ particles and then reacted with oxygen, resulting in catalyzed epitaxial growth of $\mathrm{ZnO}$ nanorods. The gas composition in the quartz furnace tube has a strong influence on the formation of $\mathrm{ZnO}$ nanorods. The diameter and size of the $\mathrm{ZnO}$ nanorods can be tuned by controlling the thickness of the evaporated $\mathrm{Au}$ and the growth time, respectively. A more detailed description of our VLS processes can be found in [81].

The ACG method mainly followed the method described in [82]. The $\mathrm{ZnO}$ nanorods were grown using zinc nitrate hexahydrate $\left[\mathrm{Zn}\left(\mathrm{NO}_{3}\right)\right)_{2} .6 \mathrm{H}_{2} \mathrm{O}, 99.9 \%$ purity] and methamine $\left(\mathrm{C}_{6} \mathrm{H}_{12} \mathrm{~N}_{4}, 99.9 \%\right.$ purity) as precursors. Before growth, the substrate was pre-treated by forming a seed layer as described in [83]. The pre-treated substrate was immersed into the aqueous solution and tilted against the wall of the beaker. The beaker was then placed into a pre-heated oven at $93{ }^{\circ} \mathrm{C}$ for five hours. The beaker was removed from the oven and cooled to room temperature, followed by washing with de-ionized water to remove any residual precursors. The detailed growth procedure using the ACG method can be found in [83-84]. The $\mathrm{ZnO}$ nanotubes were obtained using ACG-grown $\mathrm{ZnO}$ nanorods by immersing the nanorods in an aqueous solution of potassium chloride $(\mathrm{KCl})$ for seven hours at $95{ }^{\circ} \mathrm{C}$. The parameters 
were optimized, e.g., nanorod morphology, immersion time, $\mathrm{KCl}$ concentration, etching temperature, etc., and these optimized parameters were used to fabricate the nanotubes to the required depth [68].

Figure 12. Schematic diagram showing the quartz tube furnace typically used for the vapor liquid solid growth of $\mathrm{ZnO}$ nanorods.

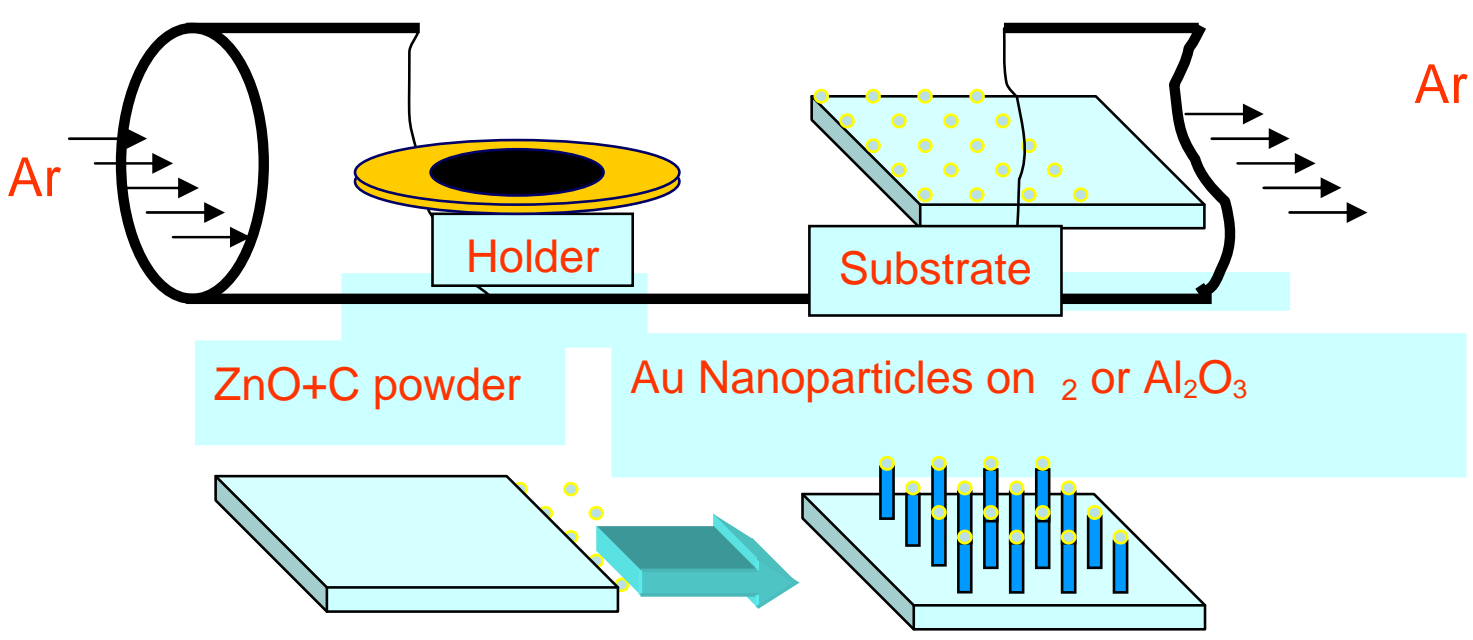

All LEDs were processed using the same steps. The only difference was in the ohmic contact to the substrate. Depending on the substrate material (p-SiC, p-GaN, or p-polymer), the appropriate metal was first deposited onto a small part of the substrate; this was followed by the ACG growth method. This step was performed after growth when using the VLS growth technique due to the high temperature during growth. In the case of $\mathrm{p}-\mathrm{SiC}$ and $\mathrm{p}-\mathrm{GaN}$, the metal deposition was followed by annealing to form an intimate contact with low contact resistivity. The part of the substrate that was covered with the ohmic contact was protected and the growth was then performed as described above. Before forming the $\mathrm{ZnO}$ nanorod ohmic contact, an insulating layer was deposited to avoid shortage between the top $\mathrm{ZnO}$ ohmic contact and the substrate. To achieve this insulation, a photoresist was spin-coated onto the $\mathrm{ZnO}$ nanorods after protecting the area used for ohmic contact with the substrate. After spinning the photoresist, low power oxygen plasma reactive ion etching was performed. This step was used to expose a small part of the nanorods to form the $\mathrm{ZnO}$ ohmic contact. Aluminum followed by platinum was used as the top non-alloyed ohmic contact to $\mathrm{ZnO}$.

\section{Conclusions}

This paper discussed $\mathrm{ZnO}$ deep level centers and the origin of the broad band(s) related to defect emission based on recently published results. Although there has been no consensus on the origin of the visible deep level emission bands in $\mathrm{ZnO}$, recent results indicate that the broad green emission band might have multiple sources. Recent comparative studies on samples grown by different techniques show that although a broad defect band is present, the center of the broad defect band is different in different samples. This is due to the fact that different samples will contain different concentrations of deep levels and other complexes due to the different growth environments. Samples grown in Zn-rich or O-rich environments will both show broad bands, but they will be centered at different wavelengths. Despite the fact that no consensus has been reached, $\mathrm{ZnO}$ emits all of the visible 
colors due to deep level centers. With proper optimization of the growth conditions, it is possible to reproduce $\mathrm{ZnO}$ nanorods with the same luminescence properties. Because $\mathrm{ZnO}$ possesses the property of self-organization combined with the small footprint of nanorods, $\mathrm{ZnO}$ nanorods can be grown on a variety of p-type substrates, avoiding the difficulty of doping $\mathrm{ZnO}$ to p-type. We have demonstrated different white light emitting diodes based on $\mathrm{ZnO}$ nanorods and crystalline p-type semiconductors, including 4H-p-SiC and p-GaN. Moreover, $\mathrm{ZnO}$ nanotubes with a much larger surface area to volume ratio were employed to fabricate $\mathrm{ZnO}$-based LEDs. Using $\mathrm{ZnO}$ nanotubes resulted in a broader spectrum, leading to improvement of the white light quality. This is probably due to the enhanced deep level defects associated with complexes adsorbed at the surface of the nanotube. Growth at temperatures as low as $50{ }^{\circ} \mathrm{C}$ has been demonstrated and shown to yield $\mathrm{ZnO}$ nanorods with excellent visible luminescence. This low growth temperature allows the combination of luminescent $\mathrm{n}-\mathrm{ZnO}$ nanorods and p-type polymers on flexible plastic. This hybrid technology could lead to the development of large-area white lighting technology.

\section{References and Notes}

1. Bunn, C.W. The lattice dimensions of zinc oxide. Proc. Phys. Soc. London 1935, 47, 835-842.

2. Willander, M.; Nur, O.; Zhao, Q.X.; Yang, L.L.; Lorenz, M.; Cao, B.Q.; Zuniga Perez, J.; Czekalla, C.; Zimmermann, G.; Grundmann, M.; Bakin, A.; Behrends, A.; Al-Suleiman, M.; AlShaer, A.; Che Mofor, A., Postels, B.; Waag, A.; Boukos, N.; Travlos, A.; Kwack, H.S.; Guinard, J.; Le Si Dang, D. Topical review: Zinc oxide nanorods based photonic devices: Recent progress in growth, light emitting diodes and lasers. Nanotechnology 2009, 20, 332001.

3. Ahn, H.A.; Kim, Y.Y.; Kim, D.C.; Mohanta, S.K.; Cho, H.K. A comparative analysis of deep level emission in ZnO layers deposited by various methods. J. Appl. Phys. 2009, 105, 013502.

4. Liu, W.; Gu, L.S.; Ye, D.L.; Zhu, S.M.; Liu, S.M.; Zhou, X.; Zhang, R.; Shi, Y.; Hang, Y.; Zhang, C.L. Blue-yellow $\mathrm{ZnO}$ homo-structural light emitting diode realized by metal organic chemical vapour deposition technique. Appl. Phys Lett. 2006, 88, 092101.

5. Gao, P.X.; Ding, Y.; Wang, Z.L. Crystallographic orientation aligned ZnO nanorods grown by Tin catalyst. Nano. Lett. 2003, 3, 1315-1320.

6. Klingshirn, C. Review article: ZnO: From basics towards applications. Phys. Stat. Sol. B 2007, 244, 3027-3073.

7. Klingshirn, C.; Mollwo, E. Light scattering experiments with heavily Li-doped ZnO crystal. Zeitschrift fur Physik A 1972, 254, 437-446.

8. Lander, J.J. Reactions of Lithium as a donor and an acceptor in ZnO. J. Phys. Chem. 1960, 15, 324-334.

9. Zwingel, D. Trapping and recombination processes in the thermoluminscence of Li-doped $\mathrm{ZnO}$ single crystal. J. Lumin. 1972, 5, 385-405.

10. Look, D.C.; Claflin, B. P-type doping and devices based on ZnO. Phys. Stat. Sol. B 2004, 241, 624-630.

11. Özgür, Ü.; Alivov, Ya.I.; Liu, C.; Teke, A.; Reshchikov, M.A.; Dogan, S.; Avrutin, A.; Cho, S-J.; Morkoç, H. A comprehensive review of $\mathrm{ZnO}$ materials and devices. J. Appl. Phys. 2005, 98, 041301-103. 
12. Gao, P.X.; Wang, Z.L. High-yield synthesis of single crystal nano-springs of ZnO. Small 2005, 1, 945-949.

13. Fuller, M.L. Twinning in zinc oxide. J. Appl. Phys. 1944, 15, 164-170.

14. Janotti, A.; van de Walle, C.G. Native point defects in ZnO. Phys. Rev. B 2007, 76, 165202-165222.

15. van de Walle, C.G.; Neugebauer, J. First principle calculations for defects and impurities: applications to III-nitrides. J. Appl. Phys. 2004, 95, 3851-3879.

16. Mooney, P.M. Identification of Defects in Semiconductors in Semiconductors and Semimetals; Academic press: San Diego, CA, USA, 1999; Volume 51B, pp. 93-152.

17. Look, D.C.; Hemsky, J.W.; Sizelove, J.R. Residual native shallow donors in ZnO. Phys. Rev. Lett. 1999, 82, 2552-2555.

18. Kröger, F.A. The Chemistry of Imperfect Crystals; North Holland press: Amsterdam, The Netherland, 1964.

19. Tuomisto, F.; Saarinen, K.; Look, D.C.; Farlow, G.C. Introduction and recovery of point defects in electron irradiated ZnO. Phys. Rev. B 2005, 72, 085206-085211.

20. Tuomisto, F.; Saarinen, K.; Look, D.C. Irradiation induced defects in $\mathrm{ZnO}$ studied by positron annihilation spectroscopy. Phys. Stat. Sol. C 2004, 201, 2219-2224.

21. Look, D.C.; Farlow, G.C.; Reunchan, P.; Limpijumnong, S.; Zhang, S.B.; Nordlund, K. Evidence of native defect donors in n-type ZnO. Phys. Rev. Lett. 2005, 95, 225502.

22. Kröger, F.A.; Vink, H.J. The origin of florescence in sled activated ZnS, CdS, and ZnO. J. Chem. Phys. 1954, 22, 250-252.

23. Kohan, A.F.; Ceder, G.; Morgan, D.; van de Walle, C.G. First principles study of native point defects in ZnO. Phys. Rev. B 2000, 22, 15019-15027.

24. Oba, F.; Nishitani, S.R.; Isotani, S.; Adachi, H.; Tanaka, I. Energetics of native point defects in ZnO. J. Appl. Phys. 2001, 90, 824-828.

25. van de Walle, C.G. Hydrogen as a doping cause n ZnO. Phys. Rev. Lett. 2000, 85, 1012-1015.

26. Reynolds, D.C.; Look, D.C.; Jogai, B.; Morkoc, H. Similarities in the band edge and deep-center photoluminescence mechanisms in GaN and ZnO. Sol. Stat. Comm. 1997, 101, 643-646.

27. Liu, M.; Kiati, A.H.; Mascher, P. Point defects and luminescence centers in $\mathrm{ZnO}$ and $\mathrm{ZnO}$ doped with manganese. J. Lumin. 1992, 54, 35-42.

28. Bylander, E.G. Surface effects on low energy cathodoluminescence of ZnO. J. Appl. Phys. 1978, 49, 1188-1195.

29. Kassai, P.H. Electron spin resonance studies of donors in ZnO. Phys. Rev. 1963, 130, 989-995.

30. Studenikin, A.; Golego, N.; Cocivera, M. Fabrication of green and orange photoluminescence, undoped ZnO films by spray pyrolsis. J. Appl. Phys. 1998, 84, 2287-2294.

31. Yamauchi, S.; Goto, Y.; Hariu, T. Photoluminescence studies of un-doped and nitrogen-doped ZnO layers grown by plasma assisted epitaxy. J. Cryst. Growth 2004, 260, 1-6.

32. Zhao, Q.X.; Klason, P.; Willander, M.; Zhong, H.M.; Lu, W., Yang, J.H. Deep level emissions influence by O and Zn implantation. Appl. Phys. Lett. 2005, 87, 211912:1-211912:3.

33. Børseth, T.M.; Svensson, B.G.; Kuznetsov A.Y.; Klason, P.; Zhao, Q.X.; Willander, M. Identification of zinc and oxygen vacancy optical signals in ZnO. Appl. Phys. Lett. 2006, 89, 262112. 
34. Klason, P.; Børseth, T.M.; Zhao, Q.X.; Svensson, B.G.; Kuznetsov, A.Y.; Willander, M. Temperature dependence and decay times of zinc and oxygen vacancies related photoluminescence in ZnO. Sol. Stat. Commun. 2008, 145, 321-326.

35. Schirmer, O.F.; Zwingel, D. The yellow luminescence of ZnO. Sol. Stat. Commun. 1970, 8, $1559-1563$.

36. Liu, M.; Kitai, A.H.; Mascher, P. Point defects and luminescence centers in zinc oxide and zinc oxide doped with manganese. J. Lumin. 1992, 54, 35-42.

37. Wu, X.L.; Siu, G.G.; Fu, C.L.; Ong, H.C. Photoluminescence and cathodoluminescence studies of stochiometric and oxygen deficiency in ZnO. Appl. Phys. Lett. 2001, 78, 2285-2287.

38. Li, D.; Leung, Y.H.; Djurisic, A.B.; Liu, Z.T.; Xie, M.H.; Shi, S.L.; Xu, S.J. Different origin of visible luminescence in $\mathrm{ZnO}$ nanostructures fabricated by the chemical and evaporation methods. Appl. Phys. Lett. 2004, 85, 1601-1603.

39. Tam, K.H.; Cheung, C.K.; Leung, Y.H.; Djurisic, A.B.; Ling, C.C.; Beling, C.D.; Fung, S.; Kwok, W.M.; Phillips, D.L.; Ding, L.; Ge, W.K. Defects in ZnO prepared by the hydrothermal method. J. Phys. Chem. 2006, 110, 20865-20871.

40. Greene, L.E.; Law, M.; Goldberger, J.; Kim, F.; Johnson, J.; Zhang, Y.; Saykally, R.J.; Yang, P. Low temperature wafer-scale production of $\mathrm{ZnO}$ nanowires arrays. Angew. Chem. Int. Ed. 2003, 42, 3031-3034.

41. Gomi, M.; Oohira, N.; Ozaki, K.; Koyano, M. Photoluminescence and structural properties of precipitated $\mathrm{ZnO}$ fine particles. Jpn. J. Appl. Phys. 2003, 42, 481-485.

42. Djurisic, A.B.; Leung, Y.H.; Tam, K.H.; Hsu, Y.F.; Ding, L.; Ge, W.K.; Zhong, C.; Wong, K.S.; Chan, W.K.; Tam, H.L.; Cheah, K.W.; Kwok, W.M.; Phillips, D.L. Defect emissions in ZnO nanostructures. Nanotechnology 2007, 18, 095702.

43. Lima, S.A.M.; Sigoli, F.A.; Jafelicci, M.; Davolos, M.R. Luminescent properties of lattice defect correlation in zinc oxide. Int. J. Inorg. Mater. 2001, 3, 749-754.

44. Nikitenko, V. Optical and Spectroscopy of Point Defects in Zinc Oxide; Springer: Dordrecht, The Netherland, 2005; p. 69.

45. Allen, M.W.; Durbin, S.M. Influence of the oxygen vacancies on Schottky contacts to ZnO. Appl. Phys. Lett. 2008, 92, 12110.

46. Quan, D.T.; Hbib, H. High barrier height Au/InP Schottky contact with POXNYHZ interfacial layer. Solid State Electron 1993, 36, 339-344.

47. Ye, J.D.; Gu, S.L.; Zhu, S.M.; Liu, W.; Liu, S.M.; Zhang, R.; Shi, Y.; Zheng, Y.D. Blue yellow homo-structural light emitting diodes realized by metal organic chemical vapour deposition technique. Appl. Phys. Lett. 2006, 88, 182112.

48. Reddy, N.K.; Ahsanulhaq, Q.; Kim, J.H.; Hahn, Y.B. Well aligned ZnO for devices: Synthesis and characterization of $\mathrm{ZnO}$ nanorods and $\mathrm{n}-\mathrm{ZnO} / \mathrm{p}-\mathrm{Si}$ heterojunction diodes. Europhys. Lett. 2008, 81, 3800.

49. Chen, D.X.; Ling, C.C.; Fung, S.; Beling, C.D.; Mei, Y.F.; Fu, R.K.F.; Siu, G.G.; Chu, Paul K. Current transport studies of $\mathrm{n}-\mathrm{ZnO} / \mathrm{p}-\mathrm{Si}$ heterostructures grown by plasma emission ion implantation deposition. Appl. Phys. Lett. 2006, 88, 132104.

50. Lampert, M.A.; Mark, P. Current Injection in Solids; Academic press: New York, NY, USA, 1970 ; p. 59. 
51. Mott, N.F.; Gurney, R.W. Electronic Processes in Ionic Crystals; Oxford University press: Oxford, England, 1940; p. 141.

52. Bylander, E.G. Surface effects on the low energy cathodoluminescence of ZnO. J. Appl. Phys. 1978, 49, 1188-1195.

53. Zeng, H.; Li, Z.; Cai, W.; Liu, P. Strong localization effect in temperature dependence of violet blue shift emission from ZnO nano-shell. J. Appl. Phys. 2007, 102, 104307.

54. Djurisic, A.B.; Leung, Y.H.; Tam, K.H.; Ding, L.; Ge, W.K.; Chen H.Y.; Gwo, S. Green yellow and orange defect emission from $\mathrm{ZnO}$ nanostructures: Influence of excitation wavelength. Appl. Phys. Lett. 2006, 88, 103107.

55. Leiter, F.; Alves, H.; Pfisterer, D.; Romanov, N.G.; Hofmann, D.M.; Meyer, B.K. Oxygen vacancies in ZnO. Physica B 2003, 340, 201-204.

56. Lin, B.; Fu, Z.; Jia, Y. Green luminescence centers in un-doped $\mathrm{ZnO}$ film deposited on Silicon substrate. Appl. Phys. Lett. 2001, 79, 943-945.

57. Djurisic, A.B.; Leung, Y.H. Optical properties of ZnO nanostructures. Small 2006, 2, 944-961.

58. Xu, P.S.; Sun, Y.M.; Shi, C.S.; Xu, F.Q.; Pan, H.B. The electronic structure and spectral properties of $\mathrm{ZnO}$ and its defects. Nucl. Instrum. Methods B 2003, 199, 286-290.

59. Mattila, J.; Nieminen, R.M. Point defects complexes and broad band luminescence in GaN and AlN. Phys. Rev. B 1997, 55, 9571-9576.

60. Everhart, T.E.; Hoff, P.H. Determination of kilovolt electron energy dissipation. J. Appl. Phys. 1971, 42, 5837-5846.

61. Kanaya, K.; Okayama, S. Penetration and energy loss of electrons in solids. J. Phys. D 1972, 5, $43-58$.

62. Dierre, B.; Yuan, X.L.; Ohashi, N.; Sekiguchi, T. Effect of specimen preparation on the cathodoluminescence properties of ZnO nano-particles. J. Appl. Phys. 2008, 103, 083551.

63. Yoshikawa, H.; Adachi, S. Jpn. J. Appl. Phys. 1997, 36, 6237.

64. Zhiyan, X.; Morihro, O.; Masayoshi, I.; Tadashi, I.; Gui, H.; Yoichiro, N.; Toru, A.; Hidenori, M. Cathodoluminescence properties of tower like $\mathrm{ZnO}$ prepared by thermal oxidation. J. Surf. Sci. Nanotech. 2009, 7, 358-361.

65. Young, M.O.; Kyung, M.L.; Kyung, P.H.; Yongsun, K.; Ahn, Y.H.; Ji-Yong, P.; Soonil, L. Correlating luminescence from individual $\mathrm{ZnO}$ nanostructures by electronic transport characteristics. Nano Lett. 2007, 7, 3681-3685.

66. Chien-Lin, K.; Ruey-Chi, W.; Jow-Lay, H.; Chuan-Pu, L.; Yi-Feng, L.; Cheng-Yu, W.; HungChin, C. ZnO with two spatially distinct light emissions. Nanotechnology 2008, 19, 285703.

67. Vanheusden, K.; Seager, C.H.; Warren, W.L.; Tallant, D.R.; Voigt, J.A. Correlation between photoluminescence and oxygen vacancies in ZnO phosphors. Appl. Phys. Lett. 1996, 15, 403-405.

68. Israr, M.Q.; Sadaf, J.R.; Yang, L.L.; Nur, O.; Willander, M.; Palisaitis, J.; Persson, P.O.Å. Trimming of aqueous chemically grown $\mathrm{ZnO}$ nanotubes and their comparative optical properties. Appl. Phys. Lett. 2009, 95, 073114.

69. Vayssieres, L.; Keis, K.; Hagfeldt, A.; Lindquist, S.E. Three dimensional array of highly oriented ZnO micro-tubes. Chem. Mater. 2001, 13, 4395-4398.

70. Fang, Z.; Wang, Y.; Xu, D.; Tan, Y.; Liu, S. Blue luminescent centers in ZnO deposited on Si substrates. Optical Mater. 2004, 26, 239-242. 
71. Alivov, Y.I.; van Nordstrand, J.E.; Look, D.C.; Chukichev, M.V.; Ateav, B.M. Observation of $430 \mathrm{~nm}$ electroluminescence from $\mathrm{ZnO} / \mathrm{GaN}$ heterojunction light emitting diodes. Appl. Phys. Lett. 2003, 83, 2943-2945.

72. Reshchikov, M.A.; Yi, G.-C.; Wessels, B.W. Behavior of 2.8- and $3.2 \mathrm{eV}$ photoluminescence bands in Mg-doped GaN at different temperatures and excitation densities. Phys. Rev. B 1999, 59, 13176-13183.

73. Nadarajah, A.; Word, R.C.; Meiss, J.; Knenkamp, R. Flexible inorganic nanowires light emitting diode. Nano Lett. 2008, 8, 534-537.

74. Zhang, T.; Xu, Z.; Qian, L.; Tao, D.L.; Teng, F.; Xu, X.R. Influence of ZnO nanorods on the luminescence properties of the fluorescent dye-doped polymer nano-composite. Opt. Mater. 2006, 29, 216-219.

75. Wadeasa, A.; Beegum, S.L.; Raja, S.; Nur, O.; Willander, M. The demonstration of hybrid n-ZnO nanorod/p-polymer heterojunction light emitting diodes on glass substrate. Appl. Phys. A-Mat. Sci. Process. 2009, 95, 807-812.

76. Wadeasa, A.; Nur, O.; Willander, M. The effect of the interlayer design on the electroluminescence and electrical properties of $\mathrm{n}-\mathrm{ZnO} / \mathrm{p}$-type blended polymer hybrid light emitting diodes. Nanotechnology 2009, 20, 065710.

77. Huang, Z.; Xu, Z.; Zhao, S.; Li, Y.; Zhang, F.; Song, L.; Wang, Y.; Xu, X. Organic-inorganic hetero-structure for enhanced electroluminescence. Solid State Commun. 2007, 142, 417-420.

78. Willander, M.; Nur, O.; Bano, N.; Sultana, K. Zinc oxide nanorods-based heterostructures on solid and soft substrates for white light emitting diodes applications. New J. Phys. 2009, 11, 125020.

79. Wagner, R.S.; Ellis, W.C. Vapour liquid solid mechanism of single crystal growth. Appl. Phys. Lett. 1964, 4, 89-90.

80. Huang, M.H.; Wu, Y.Y.; Feick, H.; Tran, H.; Weber, E.; Yang, P.D. Catalytic growth of ZnO nanowires by vapour transport. Adv. Mater. 2001, 13, 113-116.

81. Zhao, Q.X.; Klason, P.; Willander, M. Growth of $\mathrm{ZnO}$ nanostructure by vapour liquid solid method. Appl. Phys. A 2007, 88, 27-30.

82. Vayssieres, L.; Kies, K.; Lindquist, S.-E.; Hagfeldt, A. Purpose built anisotropic metal oxide material: 3D highly oriented microrod arrays of ZnO. J. Phys. Chem. B 2001, 105, 3350-3352.

83. Yang, L.L.; Zhao, Q.X.; Willander, M.; Jang, J.H. Effective way to control the size of well aligned $\mathrm{ZnO}$ nanorods with two step chemical path deposition. J. Crys. Grow. 2009, 311, 1046-1050.

84. Yang, L.L.; Zhao, Q.X.; Willander, M.; Jang, J.H.; Ivanov, I. Annealing effects on optical properties of low temperature grown $\mathrm{ZnO}$ nanorods. J. Appl. Phys. 2009, 105, 053503.

(C) 2010 by the authors; licensee Molecular Diversity Preservation International, Basel, Switzerland. This article is an open-access article distributed under the terms and conditions of the Creative Commons Attribution license (http://creativecommons.org/licenses/by/3.0/). 